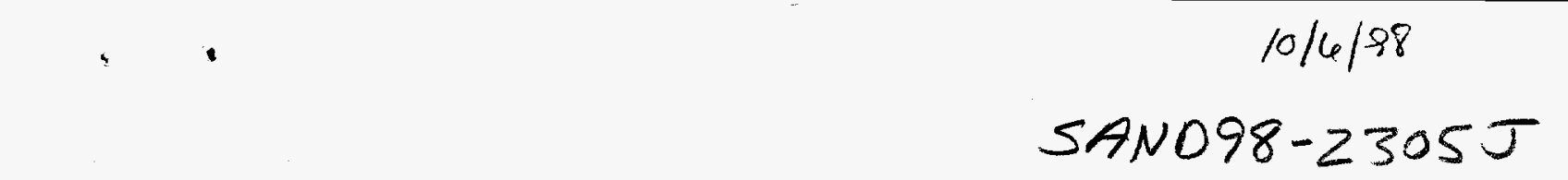

\title{
An Overview of Surface Finishes and Their Role in Printed Circuit Board Solderability and Solder Joint Performance ${ }^{1}$
}

\author{
P.T. Vianco \\ Sandia National Laboratories \\ Albuquerque, NM
}

\begin{abstract}
A overview has been presented on the topic of alternative surface finishes for package I/O's and circuit board features. Aspects of processability and solder joint reliability were described for the following coatings: baseline hot-dipped, plated, and plated-and-fused $100 \mathrm{Sn}$ and $\mathrm{Sn}-\mathrm{Pb}$ coatings; $\mathrm{Ni} / \mathrm{Au} ; \mathrm{Pd}, \mathrm{Ni} / \mathrm{Pd}$, and $\mathrm{Ni} / \mathrm{Pd} / \mathrm{Au}$ finishes; and the recently marketed immersion $\mathrm{Ag}$ coatings. The $\mathrm{Ni} / \mathrm{Au}$ coatings appear to provide the all-around best option in terms of solderability protection and wire bondability. Nickel/Pd finishes offer a slightly reduced level of performance in these areas that is most likely due to variable Pd surface conditions. It is necessary to minimize dissolved Au or Pd contents in the solder material to prevent solder joint embrittlement. Ancillary aspects that included thickness measurement techniques; the importance of finish compatibility with conformal coatings and conductive adhesives; and the need for alternative finishes for the processing of non- $\mathrm{Pb}$ bearing solders were discussed.
\end{abstract}

\section{Introduction}

Successful manufacturing operations that use solder joining processes require the bonding (or "faying") surfaces of the circuit board and package I/O (lead, termination, or castellation) to have adequate solderability. It is important to understand the functional definition of solderability in order to appreciate the role of surface finishes. Solderability includes two underlying properties, wettability and flowability or spreadability. Wettability is described as the capacity of the molten solder to interact with the base material by means of interfacial tension effects or, interfacial tension effects in combination with interfacial reaction processes, so as to develop an adherence between the liquid and the base material surface. The adherence must continue after the molten solder has solidified. The terms flowability or spreadability pertain to the molten solder being able to spontaneously cover an open surface or to fill a confined geometry such as a gap or hole by means of capillary action (Fig. 1). Wettability and flowability are not properties of equal stature. That is,

\footnotetext{
${ }^{1}$ Sandia is a multiprogram laboratory operated by Sandia Corp., A Lockheed Martin Company, for the United States Dept. of Energy under contract DE-AC04-94AL85000.
} 


\section{DISCLAIMER}

This report was prepared as an account of work sponsored by an agency of the United States Government. Neither the United States Government nor any agency thereof, nor any of their employees, make any warranty, express or implied, or assumes any legal liability or responsibility for the accuracy, completeness, or usefulness of any information, apparatus, product, or process disclosed, or represents that its use would not infringe privately owned rights. Reference herein to any specific commercial product, process, or service by trade name, trademark, manufacturer, or otherwise does not necessarily constitute or imply its endorsement, recommendation, or favoring by the United States Government or any agency thereof. The views and opinions of authors expressed herein do not necessarily state or reflect those of the United States Government or any agency thereof. 


\section{DISCLAIMER}

Portions of this document may be illegible in electronic image products. Images are produced from the best available original document. 
adequate wettability must first be present in order for the solder to then spontaneously flow and complete the joint structure (fillets, filled gaps, etc.).

It should also be noted that, under the above definitions, a particular level of wettability does not necessarily predispose a level of spreadability by the molten solder. Wettability is determined largely by the thermodynamics of the interfacial reaction(s) between the solder and the base material composition. Flowability, while also being affected by the interface reactions, is also impacted by more process-related factors such as the quantity of available solder, flux chemistry, substrate surface area and surface orientation (horizontal, vertical, or some angle related to gravity), temperature, and time. Clearly, a large number of variables affect the wettability and spreadability properties of the liquid solder and thus, impact the solderability of the molten solder/substrate/flux system as a whole. An important, albeit somewhat simplified, approach towards understanding solderability can be realized by examining Young's equation[1]. This methodology describes the thermodynamically potential, time-independent conditions for solder wetting and spreading; it does not address the kinetics of the solder/substrate reaction nor the speed of any other potential processes that may control the spreading phenomenon. The quantitative analysis is the same for the case of a liquid (solder) drop on a horizontal (substrate) surface (Fig. 2a) as well as for a vertical surface (Fig. 2b). In Young's equation, which is reproduced as equation (1) below, the quantitative metric of solderability is the contact angle, $\theta_{c}$; the smaller the value of $\theta_{c}$, better is the solderability of the solder/substrate/flux combination. The value of the contact angle is determined by the balance of interfacial tensions, $\gamma$.

$$
\gamma_{\mathrm{SF}}-\gamma_{\mathrm{SL}}=\gamma_{\mathrm{LF}} \cos \theta_{\mathrm{c}}
$$

The parameter $\gamma_{S F}$ is the interfacial tension between the substrate (S) and flux $(\mathrm{F}) ; \gamma_{\mathrm{SL}}$ is the interfacial tension between the molten solder (L) and the substrate (S); and $\gamma_{\mathrm{LF}}$ is the interfacial tension between the molten solder (L) and the flux (F). Although this equation has a computational function, it also provides important physical insight into the factors affecting solderability, and therefore, can be used to understand the role of surface finishes. The goal of minimizing $\theta_{\mathrm{c}}$ is realized by maximizing $\gamma_{\mathrm{SF}}$ while minimizing $\gamma_{\mathrm{SL}}$ and $\gamma_{\mathrm{LF}}$ Maximizing $\gamma_{\mathrm{SF}}$ is achieved by having a clean, oxide-free substrate surface; this is the role 
of pre-cleaning processes and the most often cited task of the flux. The value of $\gamma_{\mathrm{SL}}$ reflects the metallurgical reaction between the molten solder and substrate. This interfacial tension is determined largely by the choice of solder and substrate compositions. The value of $\gamma_{\mathrm{LF}}$ is determined by the surface interaction(s) between the flux and molten solder. A significant property had by the flux in the soldering process, and which is all-to-often neglected in the analyses of solder wetting and spreading, is its role of reducing the surface tension of the molten solder. The value of $\gamma_{L F}$ is determined primarily by the composition of the flux and molten solder; however, it has also been observed that $\gamma_{\mathrm{LF}}$ is sensitive to materials removed from the substrate surface in the course of the fluxing action and solder wetting/spreading activity[2-4]. This behavior is not all that unexpected, given past studies that have shown that interfacial tension values are very sensitive to contaminants, even those present at seemingly insignificant concentrations[5]. As indicated in the cited references, this phenomenon has particular significance when considering the solderability performance of Au-containing surface finishes because Au has a tendency to reduce the molten solder surface tension.

In a vast majority of applications, the decision to use a surface finish is based upon the premise that the desired level of solderability could not be realized with the condition of the substrate surface at the time of soldering. Inadequate substrate solderability can arise in the course of one of two general pretexts. The first case is that in which the base material surface can never be made solderable, given the specified process conditions. The surfaces of ceramics and glasses as well as those of metals such as $\mathrm{Al}$ or one of the refractory metals (W, Nb, Mo, etc.), would exemplify this situation. Oxides are a fundamental constituent of ceramics and glasses and thus, simply cannot be eliminated form the surfaces of those materials. Refractory metals form very tenacious, unsolderable oxide layers almost immediately when the material comes into contact with air. Under these circumstances, a surface coating must be added in order to provide a solderable "surface" to which the solder will wet and spread; the solder will not contact the underlying base material.

A second situation in which a surface finish would be considered is when the proper solderability can be obtained initially for the base material surface, but that the solderability will deteriorate excessively in the time interval between when the surface is prepared and when the soldering process takes place. Degradation of base metal solderability can arise from prolonged storage periods in which ambient air causes excessive re-oxidation of the faying surfaces. Also, corrosion products can form on the surface due to high humidity conditions in storage. A surface finish can have two potential 
roles under these circumstances. (1) Like the previous instances of glasses, ceramics or refractory metals, the underlying base metal is isolated from the molten solder by a finish that provides the solderable layer to which the solder wets and over which it spreads to form the joint. (2) The applied finish simply coats the base metal in order to seal it against excessive oxidation or contamination. During the soldering operation, the surface finish is either dissolved into the solder as is typically the case with metal coatings, or it is dissipated by the process heat just before solder spreading as occurs with several organic coatings.

Solderability can also deteriorate due to the exposure of surfaces to deposited, airborne contaminants such as dust, "acid rain" components, lubricant aerosols, or even farm chemicals. The nature and magnitude of these contaminants will depend upon the localized plant environment as well as nearby industrial and agricultural operations. In addition, the handling of exposed surfaces by humans has been documented as a everoccurring source of surface contamination and cause of subsequent solderability loss. However, under these conditions, it is important to realize that surface finishes may not always be capable of ameliorating poor solderability. For example, the initial wetting and spreading action of the molten solder takes place over the exposed surface of the top most finish layer. Deposited contaminants such as lubricants and hand oils can result in a loss of solderability of the coating surface, and therefore, degrade the overall solderability of the part.

Besides solderability protection, a second reason for the use of a surface finish is when it acts as a barrier layer between the solder and the underlying substrate material. A barrier layer is often required to prevent excessive base metal dissolution during soldering, particularly those processes using high melting temperature solder compositions. The barrier layer approach is not only used to eliminate dissolution of the base material by the molten solder, but it can also curb excessive solid-state intermetallic compound layer growth such as may occur during high temperature service. This latter point becomes particularly important when the base material has a very thin section (e.g., the $\mathrm{Cu}$ features on printed circuit boards).

In order to appreciate the effect of surface finishes on solderability retention, it is important to understand the role that such layers have during the actual solder wetting and spreading process as it occurs during formation of a joint. This point will be exemplified by the commonly-used, double-layer technique. This approach uses two metal finishes (Fig. 3), one being the solderable layer and the other, the protective layer. The metal layers may be deposited by electroplating, electroless plating, physical vapor deposition (sputtering or evaporation), or by thermal spraying. The purpose of the solderable layer is to provide the final surface to which the molten solder will wet and then subsequently 
adhere upon solidification. The protective layer, as the terminology implies, protects the solderability of the underlying solderable layer surface from being degraded by exposure to the ambient environment. Of course, in the event that adequate solderability can be achieved on the base material surface, but it simply cannot be retained under anticipated storage conditions, then only a single coating that serves as a protective finish may be required.

The wetting and spreading process of molten solder over the double metal layer case is described here (Fig. 3). Joint formation begins with the liquid solder wetting and spreading over the exposed surface of the protective finish. Behind the progressing front of molten solder, the protective finish is gradually dissolved into the liquid alloy.

Eventually, the protective layer is fully consumed into the molten solder, exposing the latter to the surface of the solderable layer. This surface, which must be pristine, is then wetted by the solder. The solder has already spread over that surface so that the flowability properties of the solderable finish are not critical to joint formation. Finally, it is important to understand that once exposed to the molten solder, the solderable finish is also subjected to dissolution by the molten solder until solidification has occurred.

The thicknesses of the solderable and protective layers must be closely controlled. The more important limit to be followed for the solderable layer is that of maintaining a specified, minimum layer thickness. As noted above, the molten solder will begin to dissolve the solderable finish upon contact. Should the layer be too thin for the prescribed time interval that the molten solder contacts it, it will be fully consumed during the soldering process, thereby exposing the molten solder to the underlying base material surface. Because the purpose of the solderable layer is to accommodate an unsolderable base material surface, there is no reason to believe that the base material surface has been made solderable, either intentionally or by means of the plating process. In fact, it should always be presumed that the underlying base material surface is not solderable. Once the molten solder reaches the unsolderable base material surface, the molten solder dewets from the surfaces. In this regard, and when specifying the thickness of the solderable layer, it is important to also consider subsequent soldering steps (repair and rework tasks) that will cause additional solderable layer dissolution. Finally, a limited amount of consumption of the solderable layer will also occur by solid-state intermetallic compound layer growth between the layer and the solder. Full transformation of the solderable finish into an intermetallic compound layer jeopardizes the integrity of the joint as there is no assurance that the intermetallic compound layer will adhere to the base metal surface.

It should be noted that dissolution of the solderable finish can potentially degrade the properties of the molten and solidified solder. However, such effects are observed 
infrequently, due in large part to the fact that traditional solderable finishes (e.g., $\mathrm{Ni}, \mathrm{Cu}$, and $\mathrm{Fe}$ ) have relatively low dissolution rates in molten solder.

Excessively thick solderable coatings have two major drawbacks. The first detriment is technically based. All coatings are deposited with some level of residual stress and contamination, the latter arising from bath components. The magnitude of each of these factors increases as the layer thickens. Overly thick layers have higher residual stresses that can be a source of delamination by the layer from the base material surface. Delamination may occur immediately after deposition or take place as a result of the thermal stresses caused by subsequent soldering processes. Excessive amounts of organic contaminants, initially hidden in thick layers, will volatize under the temperature rise of the soldering process. A minimal effect will simply be an increase in void formation in the solder. On the other hand, the violent volatilization of the organic components can actually break up the coating and/or aggravate delamination defects.

The second drawback of excessively thick solderable coatings is economically based. Simply, thick coatings result in an unnecessary cost penalty caused by both prolonged manufacturing time and excessive material waste.

Optimization of the thickness of the protective layer is also based upon a number of premises, several of which are unique to this structure. Too thin a protective coating can allow small pin holes, fissures, and other breaches to compromise the layer, causing oxidation and/or contamination of the underlying solderable layer surface that leads to poor solderability performance. Also, electroplated films are subjected to thickness fluctuations caused by variations in the throwing power of the bath over the part surface. Such fluctuations, when combined with very thin films, can result in too thin a layer or, no layer at all, to provide adequate protection over some portions of the underlying surface. Such variations are less prevalent with electroless (autocatalytic) and immersion (conversion) coatings.

Some drawbacks of excessively thick protective finishes are the same as those described for the case of solderable layers. Unnecessarily long manufacturing time and costly material waste are also applicable to protective finishes. In fact, cost penalties can become particularly burdensome because many protective layers are comprised of the precious metals $\mathrm{Au}, \mathrm{Pt}, \mathrm{Pd}$, or $\mathrm{Ag}$. Also, residual stresses in the coatings will increase as the layers thicken. Although precious metal coatings are sufficiently ductile ("soft") to relieve such stresses, thicker layers increase the chance that they will delaminate from the underlying solderable finish. Delamination of the protective finish exposes the surface of the solderable layer to oxidation and/or environmental contamination that will degrade the latter's solderability. 
A more important consequence of overly thick protective finishes is their effect on the properties of the solder and thus, the performance of the solder joint. Recall that the protective finish is fully dissolved into the molten solder during the latter's wetting and spreading activity (Fig. 3). If the coating composition differs from that of the molten solder, then the coating material becomes, in fact, a contaminant to the solder in the joint. As the coating becomes thicker relative to the quantity of solder comprising the solder joint volume, it will have a greater effect on the composition and therefore, the properties of the solder once it has dissolved. The compositional change can cause an increase in the solder's liquidus temperature, resulting in premature solidification of the solder before the joint is completely formed. Contaminants may also decrease the solidus temperture of the solder, thus reducing the maximum service temperature to which the joint can be exposed. High contamination levels can lead to reductions in the mechanical strength and ductility properties of the solder after solidification (e.g., Au embrittlement). These problems can be particularly acute for solder that must fill confined geometries such as gaps and holes or solder joints for fine-pitched, surface mount circuit boards. The small quantities of solder will experience higher contamination levels from the dissolved layer(s), resulting in a greater impact to their properties and that of the joint, before and after solidification.

Lastly, excessively thick protective finishes can degrade the service performance of a solder joint if the layer has not been fully dissolved into the solder during the soldering process. That is because solder attachment ends up being made to the protective finish rather than to the underlying solderable layer. In the case of precious metals, the solder/protective layer interface becomes prone to significant solid-state, intermetallic compound layer growth during service. The intermetallic compound layer may weaken the joint simply by its presence. Or, in the event that the remaining protective layer is fully consumed during service by the formation of an intermetallic compound layer, a new interface will have formed between the intermetallic compound layer and the solderable finish (Fig. 4). Very little properties data exists for such a joint structure. Therefore, this interface may have questionable integrity or, in the worst case, cause catastrophic failure of the interconnect.

\section{Surface Finish Systems}

Several commonly used surface finishes and structures are described below. Each system is provided with a brief description that includes advantages and disadvantages to their use.

Hot-Solder (Tin) Dipped Finishes (including Hot-Air Solder Leveling or HASL) 
Hot-solder dipped coatings or hot-Sn dipped coatings (or simply "hot-dipped" coatings) refer to those procedures by which a solder or 100Sn coating, respectively, is applied to the appropriate surface by the immersion of that surface into a bath of the molten alloy or metal. The terms "pre-tinned coatings" and "pre-tinning processes" that have been used to refer to this category of finishes in the past, are now discouraged from use because they present a great deal of confusion. Often, the listener is uncertain whether a speaker using the "pre-tin-" terminology is referring to $100 \mathrm{Sn}$ or an alloy (e.g., 63Sn-37Pb) coating composition, or whether the coating is, in fact, deposited by hot-solder dipping or electroplating processes. Hot-solder dipped finishes require that the underlying base metal surfaces be solderable, not only for the finish to coat the surface, but also because the hotdipped finish is dissolved into the molten (process) solder so that the final joint is made to the base metal below it.

The hot-solder dipping technique is often used to replace precious metal, protective finishes on component leads with a solder coating prior to the actual soldering step for board assembly. This procedure prevents the precious metal from dissolving into the solder and possibly embrittling the solder joint. It has been learned that multiple immersions are often required to insure removal of the protective finish; in fact, smaller leads may need as many as three immersions to completely remove dissolved precious metal from the subsequent solder coating, so that it is not "transferred" into the joint at the time of final circuit board assembly[6].

An important variation of the hot-solder dipping technique was developed for coating applications on printed circuit board features. That process is referred to as the hotair solder leveling, or HASL, procedure. The HASL technique is shown schematically in Fig. 5. The circuit board is coated with flux and then immersed into the bath of molten solder. The board is then withdrawn and immediately passed between two hot air jets which blow-away excess molten solder from the pads. A thin, coating of solder is left on the exposed, conductive features. An improvement to this procedure uses jets of hot oil to remove excess solder (the so-called "hydrosqueege" process); this approach is able to provide thinner solder layers. Although the illustration in Fig. 5 shows a vertical orientation to the process, horizontal HASL equipment has been developed to accommodate in-line manufacturing processes.

The recommended thickness for hot-solder dipped coatings (solder alloys or 100Sn), as listed per MIL-STD-1276D, is $1.5 \mu \mathrm{m}$ minimum and $5.1 \mu \mathrm{m}$ ) maximum as measured at the crest.

The soldering process begins by the molten solder wetting and spreading over the surface of the coating. In the case of the $\mathrm{Sn}-\mathrm{Pb}$ coating, the protective finish is melted into 
the molten solder; the condition of the surface of the solder coating is of lesser consequence here because surface (and its oxide film) breaks up during melting. In the case of Sn, however, melting of the $\mathrm{Sn}$ coating may not occur if the molten (process) solder temperature is below the melting temperature of $S n, 232^{\circ} \mathrm{C}$. Rather, the $\mathrm{Sn}$ layer is dissolved into the molten solder. In this latter case, the solderability of the Sn coating surface is much more important to the overall solderability of the I/O or circuit board pad. Therefore, the coating surface must not be so contaminated or heavily oxidized that traditional electronic fluxes are unable to break down the oxide and promote the initial wetting and spreading stage over the Sn layer.

Hot-solder dipped films provide excellent solderability protection of the underlying surface because the films are $100 \%$ dense, assuming of course, that void formation is minimized. These films are used when long-term protection must be provided to the solderable surface. A second advantage of hot-solder dipped films is that their application also provides an indication of the solderability of the base material surface. Therefore, should that solderability be poor, the hot-solder dipping step will detect this deficiency before the final assembly step and thus, prevent the need for costlier rework and repair activities on assembled circuit boards later on. A third advantage to the hot-solder dipping process is that any solder composition can be applied to the part. This point is an advantage as compared to the case of electroplated or electroless coatings (see below) in which the finish composition is limited to available bath chemistries which do not represent the wide range of available solder compositions. Fourth, the solderability of hot-dipped coated parts is of such a high level that only a relatively mild flux (" $R$ " flux or a low-solids flux) is needed for the final soldering assembly step. The flux is required to remove the oxide layer from the surface of the solder or Sn coating and to lower the surface tension of the molten solder to improve spreadability. Lastly, hot-solder dipped coatings can be applied to the package V/O's or to the printed circuit board features after each has completed their respective manufacturing steps. Therefore, the hot-solder dipping process need not be compatible with the manufacturing steps used to make the respective products; it needs to only be compatible with the temperature limits of the product materials since the hotdipping step is another soldering process.

A number of disadvantages are associated with the hot-solder dipping process; they stem largely from the fact that it is a soldering operation[7,8]. It must be made certain that the high temperature exposure to molten solder does not degrade the component or printed circuit board (HASL process). In the latter case, degradation may appear in the form of delamination of the conductor features from the underlying laminate, measling, and board warpage due to improper handling while the board is still hot. The potential for heat-related 
problems is increased further when hot-solder dipping operations are performed with higher temperature solders. In addition, proper solderability of the circuit board features or package I/O'S is often provided by the use of stronger flux compositions (e.g., water soluble, organic acid fluxes) than would be used in actual circuit board assembly. Thus, the residues from those fluxes must be thoroughly removed prior to storage or follow-on assembly processes. Lastly, solder oils placed on top of the solder bath to limit dross formation will deposit (organic) residues on the package or board. These residues require the added step of a solvent degreasing or other cleaning procedure to remove them prior to storage of follow-on assembly.

Another drawback of hot-solder dipping arises from the relatively uneven profile of the solder or $\mathrm{Sn}$ layer that is left on the I/O or circuit board pad surface. The coatings are uneven due to surface (interfacial) tension effects exhibited by the molten solder. Variations in thickness from as little as $0.8 \mu \mathrm{m}$ to as much as $38 \mu \mathrm{m}$ have been observed[8]. Although providing excellent protection against solderability loss on printed circuit boards, the "mounded" shape of the coatings interferes with the placement of finepitched and ultra fine-pitched components (leaded or leadless). The non-planar finish can result in bent leads that subsequently cause shorts or opens for peripherally leaded packages, as well as misregistered chip components that literally fall off of the solder mounds during reflow. Moreover, the quantity of solder deposited on I/O's and circuit board features (by HASL) can be excessive for the solder joints of fine-pitched package, resulting in shorts between leads as well as hindering the inspectability of the solder joints.

Lastly, the process used to apply hot-solder dipped coatings must take into account the fact that a finite degree of base material dissolution will take place by the molten solder bath. This issue becomes of particular concern when the underlying base material is a thin foil or, in fact, is another (solderable) coating for which complete base material consumption by the hot-solder dip process can potentially occur. Also, solid-state reaction processes occur between the solder and the underlying base material during long-term storage or shorter term exposure to elevated temperature environments (e.g., burn-in). The result is further growth of the intermetallic compound layer at the interface. Besides being brittle and thus, a possible site for catastrophic failure, the intermetallic compound layer growth also consumes both the solder coating and base material. In the event that the solder layer is fully consumed, the resulting intermetallic compound layer is exposed to the air. It has been observed that the $\mathrm{Cu}_{6} \mathrm{Sn}_{5}$ intermetallic compound that forms between $\mathrm{Cu}$ and $\mathrm{Sn}$-based solders or $100 \mathrm{Sn}$ is quickly oxidized by air exposure and becomes unsolderable with traditional fluxes[9]. Solid-state growth of the intermetallic compound 
layer between $\mathrm{Cu}$ and hot-solder dipped $63 \mathrm{Sn}-37 \mathrm{~Pb}$ solder and $100 \mathrm{Sn}$ coatings is described by the following equations $\left(70-170^{\circ} \mathrm{C}\right)[10]$ :

$(63 \mathrm{Sn}-37 \mathrm{~Pb})$

$(100 \mathrm{Sn})$

$$
\begin{aligned}
& \mathrm{x}=\mathrm{x}_{\mathrm{o}}+1.075 \times 10^{-2} \mathrm{t}^{0.36} \exp [-5532 /(\mathrm{T}+273)] \\
& \mathrm{x}=\mathrm{x}_{\mathrm{o}}+1.470 \times 10^{-2} \mathrm{t}^{0.46} \exp [-6375 /(\mathrm{T}+273)]
\end{aligned}
$$

where $\mathrm{x}$ is the layer thickness in meters $(\mathrm{m}) ; \mathrm{x}_{\mathrm{o}}$ is the initial layer thickness $(\mathrm{m})$; $\mathrm{t}$ is the time in seconds (s); and $\mathrm{T}$ is the temperature in Celsius $\left({ }^{\circ} \mathrm{C}\right.$ ).

Equations (2) and (3) predict the thickness of the intermetallic compound layer that is formed during growth over time, $t$, and temperature conditions, $T$. However, the amounts of $\mathrm{Sn}$ and $\mathrm{Cu}$ that are consumed by that growth depend upon the chemistry of the intermetallic compound layer. $\mathrm{The} \mathrm{Cu}_{6} \mathrm{Sn}_{5}$ stoichiometry dominates the layer formation between $\mathrm{Sn}$ and $\mathrm{Sn}$-based solders and $\mathrm{Cu}$, even up to moderate aging temperatures $\left(135^{\circ} \mathrm{C}\right)$. The $\mathrm{Cu}_{6} \mathrm{Sn}_{5}$ intermetallic compound chemistry has a density of approximately 8.3 $\mathrm{g} / \mathrm{cm}^{3}[11]$. Therefore, each "unit" of $\mathrm{Cu}_{6} \mathrm{Sn}_{5}$ thickness consumes 0.36 units of $\mathrm{Cu}$ thickness and 0.69 units of $\mathrm{Sn}$ thickness.

The process of $\mathrm{Sn}$ consumption in $63 \mathrm{Sn}-37 \mathrm{~Pb}$ alloy coatings is only slightly more complicated by the fact that the coating is not entirely $\mathrm{Sn}$. In this case, the $\mathrm{Pb}$ component does not participate in the layer formation; rather, it is rejected from the intermetallic compound layer and accumulates at the solder/intermetallic compound layer interface (Fig. 6). The seemingly faster rate of (total) coating thickness loss that would be caused by the lower $\mathrm{Sn}$ content is offset by the accumulation of the $\mathrm{Pb}$-rich layer. There is no evidence that the $\mathrm{Pb}$-rich layer impacts the intermetallic compound layer growth kinetics or mechanical integrity of the joint. However, it will affect the overall solderability of the part. The increasing $\mathrm{Pb}$ content of the coating raises the latter's melting temperature so that rapid dissolution of the layer is lost, thereby slowing the wetting and spreading rate by the molten solder. Secondly, some degradation of the solderability of the high-Pb coating can be expected since the oxide of $\mathrm{Pb}$ is more tenacious than is that of $\mathrm{Sn}$ which predominates the $\mathrm{Sn}-\mathrm{Pb}$ alloy coating.

\section{Electroplated-and Electroless Plated Solder and Sn Finishes}

Solder and Sn finishes can also be applied to package I/O's and printed circuit boards using electroplating (100Sn and $\mathrm{Sn}-\mathrm{Pb}$ alloys) and electroless plating (100Sn) techniques. In general, plating processes must be compatible with the overall process stream used to make the component package or the manufacturing steps used to make 
printed circuit boards. Electroplating processes require that the surfaces to be plated are electrically connected to the cathode of the plating bath. This constraint results in package lead frames being plated before installation into the package molding. In the case of printed circuit boards, electroplated finishes are typically applied over the entire panel surface. Then, patterning by phototolithography, coupled with chemical etching techniques, are used to define the individual features on the circuit board surface. While, hypothetically, electroplated layers can be built-up to unlimited thicknesses, adequate working values have been established in MIL-STD-1276D and are 7.6-13 $\mu \mathrm{m}$ for 100Sn and 2.5-23 $\mu \mathrm{m}$ for Sn$\mathrm{Pb}$ finishes; these values provide suitable protection of solderable surfaces without costly waste of material and manufacturing time, assuming that they are applied using practices of recommended power levels, fixture design, and monitored bath purities. Layer thicknesses of $5 \mu \mathrm{m}$ have been confirmed to provide excellent solderability protection for several years[12].

A recurring topic in discussions of plated $\mathrm{Sn}$ coatings for electronic applications is that of $\mathrm{Sn}$ whisker formation. A majority of the experimental work relating to this topic has been performed on electroplated Sn coatings; electroless $\mathrm{Sn}$ deposits are believed to be less susceptible to whisker growth[13]. Whisker growth is sensitive to such properties as: (1) coating thickness, (2) co-deposited, organic contaminants, (3) coating stresses, (4) inorganic contaminants, and (5) environmental conditions (time, temperature, and humidity). These factors appear to have synergistic roles in the formation or suppression of whiskers. Although this synergism prevents specific predictions of whisker development, some generalized trends have been observed. (1) Whisker formation appears to be less likely on very thin Sn layers (below $0.5 \mu \mathrm{m}$ ) or very thick layers $(7-10 \mu \mathrm{m})[14]$. (2) An important, contributing factor for whisker growth is compressive residual stresses in the film $[15,16]$. Those stresses can be intrinsic to the film or the result of externally applied loads. (3) Organic contaminants encourage whisker formation indirectly by causing an increased build-up of compressive residual stresses in the film and by their promotion of fine, irregular grain sizes as is the case for bright finishes[17-19], Therefore, matte $\mathrm{Sn}$ finishes are preferred to bright $\mathrm{Sn}$ coatings because the former electroplated coatings have significantly lower organic contents. (4) Besides electroless coatings, plated and thermally annealed ( 4 hours, $191^{\circ} \mathrm{C}-218^{\circ} \mathrm{C}$ ), plated and fused, or hotdipped Sn coatings are preferred because they have minimal residual stresses to cause whisker growth[20-22]. (5) Tin whiskers can grow under nearly any environmental condition, including vacuum, dry vacuum and high humidity air as well as beneath organic coatings[17]. However, studies indicate that high humidity environments tend to accelerate the growth of Sn whiskers[23]. This link may be secondary, the primary factor being the 
residual (near-surface) stresses caused by accelerated oxide formation in such environments[24]. When an oxide film is present, the relaxation of the internal stresses of the coating may be non-homogeneous; the near-surface, inhomogeneous stress state provides the driving force (chemical potential) for diffusion processes that support whisker growth. That is, those areas having elevated, compressive residual stresses will be prone to whisker growth at the expense of material supplied by neighboring non-stressed regions.

(6) Tin whisker growth is also sensitive to the substrate over which the Sn coating is applied. Whiskers will most likely form when $\mathrm{Sn}$ is plated over brass[25]. X-ray studies have confirmed the presence of $\mathrm{Cu}$ and $\mathrm{Zn}$ in the composition of the whiskers tha have developed on brass substrates. Growth occurs to a lesser degree in the order of the following substrates: electroplated $\mathrm{Cu}$, wrought $\mathrm{Cu}$, steel, electrodeposited $\mathrm{Ni}$, and $35 \% \mathrm{Sn}-65 \% \mathrm{Ni}$ alloy. Copper or $\mathrm{Ni}$ can be used as a barrier layer to isolate brass substrates from the $\mathrm{Sn}$ coatings and thus, minimize whisker formation.

(7) The final factor, inorganic contaminants, has been shown to be important towards repressing whisker growth in pure $\mathrm{Sn}$ coating. Contaminant elements such as $\mathrm{Sb}$, $\mathrm{Co}, \mathrm{Cu}, \mathrm{Ge}, \mathrm{Au}, \mathrm{Pb}$, and $\mathrm{Ni}$ at levels of $1-2 \%$ appear to be effective for mitigating whisker growth in $\mathrm{Sn}$ coatings[23]. In fact, very low $\mathrm{Pb}$ concentrations, on the order of $0.5 \%$ to $5 \%$, were shown to hinder whisker formation; $\mathrm{Pb}$ levels in excess of these levels assured minimal whisker formation[20]. Note: While a number of alloy additions to the Sn film will suppress whisker growth, they can also significantly impair surface solderability, primarily due to the formation of a very tenacious oxide layer. Therefore, coating compositions should be selected that can also support the soldering process with a minimization of defects.

Electroplated coatings of $\mathrm{Sn}$ and $\mathrm{Sn} / \mathrm{Pb}$ alloy can be deposited as either matte or bright finishes. A matte finish has a dull appearance because the rough topography of the coating surface poorly reflects light. As the term suggests, the bright finish has a very shiny appearance due to a very smooth top surface. Although the bright finishes are more aesthetically pleasing and, from a functional sense, tend to resist oxidation to a greater extent because of their reduced surface area, they are not recommended for soldering applications because of several complications arising from the higher organic contents needed to realize the shiny surface. First, during intermetallic compound layer growth between the $\mathrm{Sn}$ and $\mathrm{Cu}$ layers, the organic contents of the $\mathrm{Sn}$ layer accumulate at the intermetallic compound layer/Sn interface. It is this interface that later forms the surface to which the (process) solder finally wets. The accumulated organic contaminant layer interferes with the wetting process, resulting in non-wetting and dewetting defects. Secondly, higher coating organic contents result in an increased level of void and blow- 
hole formation in solder joints when they volatize under the reflow temperature profile. Thirdly, as noted above, it is purported that bright finishes are more susceptible to whisker growth.

An innovative Sn electroplating process has been developed by Zhang and coworkers at Lucent Technology Bell Labs that is reported to be less susceptible to whisker formation and provides good surface solderability protection[26]. The process results in bright Sn coatings having low organic contents and large grain development. The large, stable grains and reduce organic contamination limit residual stresses in the coatings; it is those internal stresses which serve as the primary driving force for whisker formation.

Next, electroless coatings are discussed. The term "electroless" in electroless plating refers to the deposition of metal coatings in the absence of an applied voltage as is required by electroplating processes. The terms "immersion" and "autocatalytic" coatings distinguish between two types of electroless coating processes, although the term "electroless" is most often used in reference to the latter case[7]. Immersion platings, which are also called "galvanic" platings or "conversion" coatings, result in relatively thin layers (typically less than $1 \mu \mathrm{m}$ ) because the deposition process halts once the substrate surface is completely covered with the plated material. Autocatalytic processes use a reducing agent, usually $\mathrm{P}$ or borated compounds, to allow metal deposition to proceed after the base material has been covered. Thus, theoretically, unlimited layer thicknesses can be obtained with the autocatalytic processes. In most instances, the layer thicknesses are limited to about $5 \mu \mathrm{m}$.

Electroless processes have been developed for single element coatings (e.g., Sn, $\mathrm{Au}$, etc); they are not available for alloy depositions such as $\mathrm{Sn}-\mathrm{Pb}$. The immersion $\mathrm{Sn}$ coating process has been in existence for a considerable number of years. However, immersion Sn finishes have not found favor in the electronics industry because they have not afforded adequate solderability protection for shelf lives beyond a couple of weeks[12]. A detailed study conducted by I. Artaki, et al. found that the loss of solderability was due directly to the thickness of $\mathrm{Sn}$ oxide $\left(\mathrm{SnO}_{x}\right)$ that had formed on the coating surface[27]. In that study, the immersion Sn coating retained good solderability after two exposures to a $\mathrm{Sn}-\mathrm{Pb}$ oven reflow cycle (peak conditions: $235^{\circ} \mathrm{C}, 30-40 \mathrm{~s}$ ) using a non-inerted atmosphere. Moreover, immersion Sn coatings were able to survive dry ambient storage for 4 weeks without a significant loss of solderability as determined by the wetting balance test. However, accelerated oxide growth that resulted from the presence of high humidity conditions, severely degraded solderability. Given the heating cycles, aging conditions $\left(25^{\circ} \mathrm{C}, 4\right.$ weeks to $65^{\circ} \mathrm{C}, 1$ week), and a coating thickness that reached $1.5 \mu \mathrm{m}$, excessive intermetallic compound layer growth and resulting consumption of the Sn layer was not the 
sources of solderability deterioration. New, immersion Sn chemistries purported to have better shelf life properties are becoming commercially available[28].

Electroplated and electroless $\mathrm{Sn}$ or $\mathrm{Sn}-\mathrm{Pb}$ coatings are in intimate contact with the base material. Therefore, solid-state interface reactions will still take place between the two materials under elevated temperature conditions and prolonged time periods. Those reaction will result in intermetallic compound layer growth and consumption of both the $\mathrm{Sn}$ or solder coating and the base metal. The growth kinetics between electroplated 60Sn$40 \mathrm{~Pb}$ and $100 \mathrm{Sn}$ coatings and wrought $\mathrm{Cu}$ over the temperature range of $70^{\circ} \mathrm{C}$ to $170^{\circ} \mathrm{C}$ are described by equations (4) and (5), respectively. The data, which were obtained from Reference [29], were used by the author to calculate the equation parameters by multivariable, linear regression analysis.

$$
\begin{array}{ll}
(60 \mathrm{Sn}-40 \mathrm{~Pb}) & \mathrm{x}=6.312 \times 10^{-2} \mathrm{t}^{0.36} \exp [-3969 /(\mathrm{T}+273)] \\
(100 \mathrm{Sn}) & \mathrm{x}=6.157 \times 10^{-5} \mathrm{t}^{0.35} \exp [-2886 /(\mathrm{T}+273)]
\end{array}
$$

where $\mathrm{x}$ is the layer thickness in meters $(\mathrm{m}) ; \mathrm{x}_{\mathrm{o}}$ is the initial layer thickness $(\mathrm{m})$ and is set equal to 0 ; $t$ is the time in seconds (s); and $\mathrm{T}$ is the temperature in Celsius $\left({ }^{\circ} \mathrm{C}\right)$. As noted in the previous sections, each "unit" of $\mathrm{Cu}_{6} \mathrm{Sn}_{5}$ thickness consumes 0.36 units of $\mathrm{Cu}$ thickness and 0.69 units of $\mathrm{Sn}$ thickness. A higher melting temperature, $\mathrm{Pb}$-rich layer will gradually accumulate from the $\mathrm{Sn}-\mathrm{Pb}$ solder/Cu reaction. Complete loss of the $\mathrm{Sn}$ component of the $\mathrm{Sn}-\mathrm{Pb}$ alloy and the remaining $\mathrm{Pb}$-rich layer will slow the wetting and spreading process and/or degrade overall solderability.

It is important to recognize that $\mathrm{Sn}$ and $\mathrm{Sn}-\mathrm{Pb}$ alloy plated finishes are designed as protective (sacrificial) layers; that is, they ultimately are dissolved into the (process) solder when the joint is formed (Fig. 3). The soldering process begins by the molten solder wetting and spreading over the surface of the coating. Therefore, the coating surface must not be so contaminated or so heavily oxidized that traditional electronic fluxes cannot promote adequate solderability. The exact process by which the coating dissolves into the molten solder depends upon (1) the coating composition and therefore, its melting temperature and (2) the temperature of the solder. In the case of a $63 \mathrm{Sn}-37 \mathrm{~Pb}$ coating, contact with the similar molten solder causes the layer to simply melt and be incorporated into the molten (process) alloy. Any oxide film will be lost largely by its own breaking up as the coating melts. However, a flux is still needed in the soldering process in order to reduce the surface tension of the molten solder and improve its solderability. 
The dissolution of 100Sn finishes can be slightly more complex, depending upon the molten solder temperature. Tin melts at $232^{\circ} \mathrm{C}$. In the event that the process temperature equals or exceeds $232^{\circ} \mathrm{C}$ (e.g., wave soldering at $250^{\circ} \mathrm{C}$ to $260^{\circ} \mathrm{C}$ ), then the layer will melt into the molten solder. If the process temperature is below $232^{\circ} \mathrm{C}$ (e.g., many furnace reflow processes), then the $100 \mathrm{Sn}$ layer will dissolve into the molten solder. Because the $100 \mathrm{~S} n$ coating remains intact during the initial (process) solder wetting and spreading activity, it must have adequate solderability through minimal oxide formation, which will be significant on the preferred matte finish, and other contaminants. Thus, slightly more active fluxes may be required to realize the needed wetting and spreading by the (process) molten solder over the $100 \mathrm{Sn}$ coating surface.

A second aspect of the sacrificial nature of the plated coatings is that the solderability of the underlying base metal surface must also be satisfactory. Once the coating has been dissolved into the solder, the latter must then wet to the base metal surface. (Spreading has already been largely achieved through the solderability of the coating, itself.) If the base material has poor solderability, dewetting of the molten solder will be observed.

As was the case with hot-solder dipped coatings, the effect of coating dissolution on changes to (process) solder properties should be ascertained when the two have differing compositions (e.g., Sn finish and $60 \mathrm{Sn}-40 \mathrm{~Pb}$ process solder). Solderability properties and consequentially, soldering defects, as well as the performance of the joint in service can depend upon the degree of "contamination" posed by the coating thickness and changes to the melting properties, surface tension, and mechanical properties that ensue.

Protective coatings of $\mathrm{Sn}-\mathrm{Pb}$ solder or $100 \mathrm{Sn}$ are often preferred as electroplated finishes rather than as hot-dipped coating because plated layers have a more uniform thickness over the base material surface. Not only are plated coatings suitable for finepitched, surface mount components from the aspect of preventing damage to leads on peripheral $\mathrm{J} / \mathrm{O}$ packages, but plated coatings also provide a technique for depositing the reduced quantities of solder required by fine-pitched package solder joints. Greatest uniformity is realized with electroless coatings as compared to electroplated coatings. The thickness of electroplated coatings can vary due to spatial differences in the plating efficiency or "throwing power" of the bath. This phenomenon can be particularly troublesome with through-hole circuit boards in which the throwing power varies between the surface of the board (lands) and the interior of the holes (barrels). It is less of a consequence on strictly surface mount circuit boards unless poor plating practices are being exercised by the bath operators. 
A technique to densify plated coatings is called fusing. In the fusing process, the base material is heated to a temperature exceeding the melting temperature of the particular coating composition. The layer melts and in doing so, eliminates pinholes and other defects so as to produce a fully dense coating upon resolidification. The recommended layer thicknesses for plated and fused $63 \mathrm{Sn}-37 \mathrm{~Pb}$ coatings (and can be inferred for $100 \mathrm{Sn}$ coatings) as specified by MIL-STD-1276D is $2.5 \mu \mathrm{m}$ minimum, $7.6 \mu \mathrm{m}$ average, and 13 $\mu \mathrm{m}$ maximum. Several important aspects of fusing must be considered when considering this procedure. First of all, the fusing process entails a high temperature exposure of the component or printed circuit board. Secondly, once the solder has melted and as long as it is molten, base metal dissolution and limited intermetallic compound layer growth will take place at the solder/base metal interface. Thirdly, oxidation of the coating surface will occur during the fusing process which may degrade solderability for follow-on soldering processes.

The third point brings up an important point of fusing processes: whether or not to use a flux. A flux coating will significantly limit oxidation of the coating surface and thus certify its solderability. However, the flux will also lower the surface tension of the liquefied coating by removing the oxide skin as well as by its intrinsic effect on the now exposed liquid metal surface tension. A reduced surface tension caused by the flux allows the molten solder to more readily "flow" on the surface. The result is that the once uniform coating thickness will develop mounds of thicker coating over horizontal surfaces; it will build up at corners and at the bottoms of vertical surfaces under gravity; and the coating will flow away from edges to leave a thinned layer there (which is the source of the "weak knee" solderability defect on through holes that have plated-and-fused coatings). The extent of these phenomena as well as coating oxidation and solder/base metal interactions will depend strongly upon the chosen fusing process parameters (time, temperature, and flux, if any) as well as the compositions of the particular coating and base material.

\section{Organic Solderability Preservative (OSP) Finishes}

Organic solderability preservatives, or OSP's, are an important group of protective finishes for bare $\mathrm{Cu}$. Prior to the development of today's sophisticated compounds, rosinbased lacquers were used to provide (very) limited solderability protection for $\mathrm{Cu}$ [12]. The fact that such coatings were relatively permeable to air and, themselves, degraded quickly over time, gave temporary protection that was adequate for only high throughput assembly processes.

Three classes of compounds are currently used by the electronics industry as OSP's: benzotirazole compounds, imidazole compounds, and benzimidazole compounds. 
These newer compounds protect the $\mathrm{Cu}$ surface by actually forming a chemical bond with the $\mathrm{Cu}$ that disallows the latter's oxidation. The very uniqueness of that bond precludes the use of azole and imidazole coatings from working on any metal other than $\mathrm{Cu}$. Rather; other imidazole chemistries will have to be developed for alternative metal surfaces (e.g., $\mathrm{Ni}, \mathrm{Sn}, \mathrm{Sn}-\mathrm{Pb}$, etc.). The solderability of the underlying $\mathrm{Cu}$ surface must be excellent since that surface will ultimately support the wetting and spreading of molten solder during assembly. Fortunately, the $\mathrm{Cu}$ solderability often goes hand-in-hand with the adhesion of the OSP layer at the time that the coating is applied. Therefore, poor OSP adhesion during the coating process provides an initial indication of a significant contamination of the $\mathrm{Cu}$ surface that would also deteriorate its solderability later on.

The shelf life of printed circuit boards coated with OSP's has improved with the newer formulations. Shelf lives from $6-12$ months have been documented for office-type storage environments $\left(20-30^{\circ} \mathrm{C}, 30-70 \mathrm{RH}\right)[30]$. However, that shelf life quickly degrades with sustained exposure to higher temperatures and high humidity over prolonged time periods.

With respect to solder processing, the OSP coating functions by protecting the $\mathrm{Cu}$ surface up to the start of the soldering process. At that point, the elevated temperatures (typically $120^{\circ} \mathrm{C}$ to $150^{\circ} \mathrm{C}$ ) cause the OSP coating to dissipate into the furnace environment, thereby exposing the $\mathrm{Cu}$ surface to the flux and environment followed by wetting and spreading of the molten solder. In the event that the OSP coated $\mathrm{Cu}$ is exposed to a process cycle in the absence of flux and solder, the coating is loss as described and the $\mathrm{Cu}$ readily re-oxidizes in air reflow. It is by this latter scenario that OSP coatings have generally not provided adequate solderability protection in air after the first process cycle as would be required by double-sided surface mount or mixed technology circuit boards. Under such circumstances, protection would only be realized with metallic coatings (hot-solder dipped, electroplated, and electroless layers). Therefore, a primary objective of OSP manufacturers is to develop a coating that will survive multiple reflow cycles, yet, "disappear" when solder and flux are present to make the joint.

Solderability protection improves significantly when OSP coatings are used in conjunction with $\mathrm{N}_{2}$ atmospheres during the soldering process[30-33]. The solderability of $\mathrm{Cu}$ features is excellent for the first reflow step and remains adequate after for the second reflow cycle because the loss of the OSP coating during the first pass does not result in oxidation of the $\mathrm{Cu}$ features under the presence of the $\mathrm{N}_{2}$ atmosphere. A significant improvement in solderability is realized with $\mathrm{O}_{2}$ levels at, or below, $1000 \mathrm{ppm}[31,32]$. Moreover, having a $\mathrm{N}_{2}$ atmosphere also enhances the solderability of OSP-coated printed circuit boards being assembled with no-clean flux processes. 
The protection offered by OSP coatings is dependent upon the soldering process cycle. Generally speaking, process time and temperatures are minimized in order to prevent inadvertent loss of OSP layer prior to actual wetting and spreading by the molten solder. This caution is particularly pertinent with the use of higher temperature solders other than the traditional $\mathrm{Sn}-\mathrm{Pb}$ alloys. That is because these solders often require longer preheat times to reach the soldering process temperature. The extended preheats increase the likelihood of OSP degradation before the actual soldering event has begun.

Nevertheless, OSP-coated surface mount and through-hole circuit boards have been used successfully with reflow and wave soldering processes, respectively, performed with higher melting temperature, $\mathrm{Sn}-\mathrm{Ag}$ and $\mathrm{Sn}-\mathrm{Ag}-\mathrm{X}$ ternary, $\mathrm{Pb}$-free solders[34-36]. Excellent yields were observed in single-pass processes using an inert $\mathrm{N}_{2}$ atmosphere; moreover, the $\mathrm{N}_{2}$ atmosphere allowed for double-sided circuit boards to be satisfactorily assembled with the necessary two reflow steps[37].

OSP-coated circuit boards are particularly beneficial for fine-pitch products. The coating thickness can range from several tens to several thousands of angstroms, depending upon the particular manufacturer[33]. This limited thickness and its uniformity over the surface prevents damage to the leads of peripheral $\mathrm{I} / \mathrm{O}$ packages. As compared with the solder mounds deposited by the HASL technique, the uniform OSP coating will not interfere with the placement of smaller chip devices, as well.

\section{Gold and Nickel/Gold}

The $\mathrm{Ni} / \mathrm{Au}$ surface finish has been used extensively by the electronics industry as a solderability coating for difficult-to-solder lead materials such as steel, $\mathrm{Al}$, Kovar ${ }^{\mathrm{TM}}$, Alloy $42^{\mathrm{TM}}$, etc.[38]. The Au layer is the protective finish, and is dissolved by the molten solder as it wets and spreads over the part (Fig. 3). The final wetting by the molten solder is to the Ni solderable layer. For lead frame and structural applications, the $\mathrm{Ni}$ and Au layers are deposited by electroplating process; the sulfamate-type baths are used for the Ni coating and a cyanide bath of the Au coating. The $\mathrm{Ni}$ bath may be replaced with an electroless $\mathrm{Ni}$ (Ni-P or Ni-B bath). Layer thicknesses as recommended by MIL-STD-1276D are: Ni, 1.3$3.8 \mu \mathrm{m}(2.5-7.6 \mu \mathrm{m}$ if necessary) and $\mathrm{Au}, 1.3-2.5 \mu \mathrm{m}$.

The $\mathrm{Ni} / \mathrm{Au}$ finish scheme has recently received considerable attention for printed circuit board features. Circuit board applications use "electroless" processes almost exclusively for both the $\mathrm{Ni}$ and Au finishes. That is because the layers are deposited after the circuit board had been fabricated, when the $\mathrm{Cu}$ features are not all electrically connected as would be required for an electroplating process. 
At first, the Ni layer was omitted and the $\mathrm{Cu}$ features were coated with only a thin or "flash" layer of Au to serve as a protective finish. However, the limited thickness required of the $\mathrm{Au}$ layer to prevent solder joint embrittlement also raised concerns for "fast" $\mathrm{Cu}$ diffusing through the $\mathrm{Au}$ layer and reaching the latter's exposed surface, resulting in a loss of solderability[39]. Therefore, to prevent potential interdiffusion, a two-coating system was introduced in which the electroless $\mathrm{Ni}$ (barrier) layer was added between the $\mathrm{Cu}$ feature and the $\mathrm{Au}$ layer. Both the $\mathrm{Ni}$ and $\mathrm{Au}$ can be deposited by electroless (autocatalytic) plating processes. The $\mathrm{Ni}$ is deposited from a Ni-P solution (or new Ni-B solutions)[40]. The $P$ content can range from $5-11 \%$. Higher $P$ contents tend to reduce the ductility of the layer. Also, the $\mathrm{P}$ has a tendency to migrate to interfaces under excessive exposure to elevated temperatures such as may be used in burn-in and soldering operations, resulting in a potential loss of joint strength. Therefore, the lower $\mathrm{P}$ bath chemistries (6\%) are preferred. Electroless Ni layer thicknesses of $1.3-3.0 \mu \mathrm{m}$ are recommended by $\mathrm{MIL}-$ STD-1276D; thicker layers of $2.5-5.0 \mu \mathrm{m}$ can also be used, although they are not recommended for flex substrates because their brittle nature increases the likelihood of them being fractured. The printed circuit board industry has largely followed these guidelines for $\mathrm{Ni}$ coatings $[7,41]$.

In the case of the Au layer, it may be deposited by two processes: (1) traditional electroless (autocatalytic) technique from a bath containing an organo-boron compound that serves as the reducing agent and with the potential for unlimited thicknesses, or (2) the immersion technique ("conversion" process or "galvanic process). The MIL-STD-1276D recommended thickness for electroplated $\mathrm{Au}$ is $1.3-2.5 \mu \mathrm{m}$. Although the electroless (autocatalytic) process can deposit theoretically an unlimited Au thickness, typical thicknesses are in a similar range of between 0.5 and $2.0 \mu \mathrm{m}$. The immersion Au process results in a much thinner layer of approximately $0.05-0.2 \mu \mathrm{m}$ [42]. Because the immersion Au layers are very dense, they offer similar solderability protection as do the thicker electroless and electrolytic platings.

The quantity of $\mathrm{Au}$ that is dissolved into the molten solder must remain below a critical level of 3-4 wt\% so as to prevent embrittlement of that joint $[43,44]$. However, recent work by Mei and co-workers on plastic ball-grid array solder joints made to printed circuit boards having $\mathrm{Ni} / \mathrm{Au}$ finish has indicated that $\mathrm{Au}$ dissolved into the solder was prone to re-deposition at the solder/Ni interface as Au-Sn intermetallic compound[45]. A drop in the strength of the solder joints was subsequently observed after accelerated aging at an elevated temperature of $150^{\circ} \mathrm{C}$ and for a period of 14 days. Being based upon solid-state diffusion processes, the redeposition mechanism will be very sensitive to time and temperature environments as well as to the relative quantity of $\mathrm{Au}$ in the joint. Therefore, a 
more detailed experimental analysis is required to determine the diffusion kinetics in order to predict the rate of Au re-accumulation at the interface; then, the extent of accumulation can be correlated to the degree of strength deterioration by the solder joint and combined to comprise a predictive tool for determining service reliability.

It should be noted that the $\mathrm{Ni} / \mathrm{Au}$ finishes used on package leads and terminations also pose a similar embrittlement risk to solder joint integrity. The risk is particularly acute in this case because the electroplated Au layer thickness are relatively thick, as specified by MIL-STD-1276D recommendations $(1.3-2.5 \mu \mathrm{m})$. Therefore, it is necessary to remove the $\mathrm{Au}$ protective finish from the leads rather than let it dissolve into the solder joint during solder assembly. The removal of the Au coating is usually done with a hot-solder dip procedure in which the molten solder is used to literally wash away the Au layer, replacing it with layer of solder or $100 \mathrm{Sn}$. It was observed that as many as 3 dips may be required on smaller, beam-leaded surface mount packages to remove the $\mathrm{Au}$ to levels that do not jeopardize joint integrity[6].

The Ni/Au surface finish generally exhibits excellent solderability, both on laboratory test coupon as well as on prototype circuit boards[2,46]. Excellent solderability of printed circuit board test vehicles was retained after as many as seven process passes that included one wave soldering step and six oven reflow (air) steps; the solder joint fillets retained a shiny surface appearance. Laboratory tests have confirmed the solderability of $\mathrm{Ni} / \mathrm{Au}$ coatings after a series of pre-heat treatments[3,4]. In fact, those laboratory studies confirmed that, besides protecting the wettability of the underlying $\mathrm{Ni}$ layer by maximizing value of $\gamma_{\mathrm{SF}}$ in equation (1), the dissolved $\mathrm{Au}$ in the solder also lowered the surface tension of the molten solder; that is, it reduced $\gamma_{\mathrm{LF}}$ in equation (1), as an additional means of improving the solderability.

The interface between the Ni layer and the solder is susceptible to intermetallic compound layer growth by solid-state diffusion processes. Those processes are accelerated by elevated temperatures; the extent of growth is determined by the duration of such exposure(s). When compared to $\mathrm{Cu}$, the growth rate of intermetallic compound layer between $\mathrm{Sn}$-based solders and $\mathrm{Ni}$ is relatively slow. Available kinetics data are limited to solid-state growth between electroplated $\mathrm{Sn}$ layers and $\mathrm{Ni}$ wrought base material; that function for growth over the $70^{\circ} \mathrm{C}$ to $170^{\circ} \mathrm{C}$ temperature range is provided by equation (6). The data, which were obtained from Reference [47], were used by the author to calculate the equation parameters by a multivariable, linear regression analysis:

$(100 \mathrm{Sn})$

$$
x=2.055 \times 10^{-4} t^{0.50} \exp [-4739 /(T+273)]
$$


where $\mathrm{x}$ is the layer thickness in meters (m); $\mathrm{x}_{\mathrm{o}}$ is the initial layer thickness (m) which is set equal to $0 ; t$ is the time in seconds (s); and $\mathrm{T}$ is the temperature in Celsius $\left({ }^{\circ} \mathrm{C}\right) . \mathrm{A}$ determination of the quantity of either $\mathrm{Sn}$ or $\mathrm{Ni}$ that is consumed by the intermetallic compound layer growth is dependent upon the composition of the layer. The predominant layer chemistry is $\mathrm{Ni}_{3} \mathrm{Sn}_{4}$. The intermetallic compound has a density of approximately 8.7 $\mathrm{gm} / \mathrm{cm}^{3}[11]$. Therefore, the creation of each "unit" of $\mathrm{Ni}_{3} \mathrm{Sn}_{4}$ thickness will consume 0.26 units of Ni thickness and 0.87 units of $\mathrm{Sn}$ thickness. As alluded to earlier, intermetallic compound layer grow between $\mathrm{Ni}$ and $\mathrm{Sn}-\mathrm{Pb}$ solders will cause the build-up of a $\mathrm{Pb}$-rich layer between the remaining solder coating and the $\mathrm{Ni}_{3} \mathrm{Sn}_{4}$ intermetallic compound layer. $\mathrm{The} \mathrm{Pb}$-rich layer can negatively impact solderability as it grows thicker with solid-state aging.

\section{Nickel/Palladium}

A surface finish that is gaining increased popularity for both printed circuit board and lead surfaces is the Ni/Pd coating system. This coating sequence works in the same manner as the $\mathrm{Ni} / \mathrm{Au}$ case; Nickel is the solderable finish to which the solder ultimately wets and adheres. The Pd layer serves as the protective finish that maintains the solderability of the underlying $\mathrm{Ni}$ layer, but is consumed by the molten solder during the assembly process. A primary driving force behind the replacement of the Au protective layer with Pd is cost. Also, the electroless plating processes used to deposit Pd offers two addtional advantages over electroless Au. First, the plating process is performed from a bath chemistry which is only slightly acidic so that there is less damage to the solder mask. Secondly, the bath operates at relatively low temperatures, thus reducing thermal damage to the mask and laminate. Although Pd is also considered a precious metal, Pd is not as noble as Au. The metal does form a surface oxide, PdO. Although the oxide remains relatively thin and is not very tenacious, it, nonetheless, can result in some deterioration to solderability as compared to similarly treated $\mathrm{Ni} / \mathrm{Au}$ coated surfaces.

An important point that is brought up with regards to the use of Pd finishes is their potential to embrittle the solder joint as is the case with Au coatings. Work by Bester as well as by Duckett and Ackroyd indicated that a Au content in the solder that exceeded approximately $4 \mathrm{wt} \%$ would cause a significant loss of strength and ductility [43,44]. A recent study has indicated that a $50 \%$ reduction in the fracture toughness to $63 \mathrm{Sn}-37 \mathrm{~Pb}$ solder can be expected from Pd concentrations in excess of 1-2\%[48]. In addition, other studies confirmed that the $\mathrm{Pd}$ readily dissolved into the molten solder, but then, upon solidification, participated in the formation of $\mathrm{PdSn}_{4}$ crystals near the original plating 
interface[49]. That is, the Pd did not diffuse away from the interface as is observed with $\mathrm{Au}$, thereby increasing the chances of forming a zone of weakened (embrittled) solder along the solder/substrate interface. Therefore, the potential for solder joint embrittlement by Pd must be considered by taking into account the conditions of Pd thickness with respect to the solder volume within the joint. Because Pd does not appear to readily disperse in the solder volume, conservative estimates can be made by computing the concentration of Pd expected in the near-interface solder volume (extending approximately $10-25 \mu \mathrm{m}$ from the interface), based upon the initial thickness of Pd coating on the lead or circuit board pad.

The Ni and Pd layers used on package leads is usually applied by electroplating processes when the leads are still in the frame and not yet assembled into the package. A process developed by Texas Instruments and used by Advanced Microdevices components begins with a Ni strike applied on the lead frame surfaces to a thickness of $0.1 \mu \mathrm{m}$ [50]. Then, a thin Ni/Pd alloy layer measuring $0.01 \mu \mathrm{m}$ thick is applied, followed by the $\mathrm{Ni}$ solderable layer $(1.2 \mu \mathrm{m})$ and lastly, the Pd protective coating $(0.1 \mu \mathrm{m}$ thick). Once coated, the lead frame is then ready for separation into the individual leads. A series of cutting and forming process are used bring each lead into the desired shape (typically, the gull wing configuration).

The study cited in Reference [50] made several observations pertinent to the use of the Ni/Pd lead finish on TSOP lead frames. First of all, it was observed that the finish can be susceptible to cracks on the outer surfaces of bends that develop during poorly controlled, lead forming process. These cracks exposed the underlying lead material (in this case, $\mathrm{Cu}$ ) to the environment; oxidation (and any other contamination) caused a measured degradation to lead solderability. Proper forming tool configurations and procedures were observed to alleviate this defect. It was also noted that a minimum flux strength corresponding to that of an RMA solution (rosin-based, mildly activated) was required to attain consistent solderability, particularly when the parts were exposed to extensive temperature/humidity test environments. The pull strengths of the TSOP joints were not significantly different from those of joints having $\mathrm{Sn}-\mathrm{Pb}$ solder finishes on all surfaces. Moreover, exposing TSOP solder joints made with Ni/Pd finishes to 1068 and 2417 thermal cycles $\left(0^{\circ} \mathrm{C}, 100^{\circ} \mathrm{C}, 48\right.$ cycles/day) did not cause a significant change in the mechanical strength of the joints versus the $\mathrm{Sn}-\mathrm{Pb}$ finish. In a separate study, excellent mechanical performance following (1) static aging and (2) mechanical fatigue to SOIC gullwing leads coated with a Ni/Pd finish confirmed the robustness of solder joints made with this finish [49]. 
The Ni/Pd finishes "group" has also received considerable interest as a surface finish for the $\mathrm{Cu}$ features on printed circuit board. The group includes three finishes: (1) $\mathrm{Pd}$ only, (2) Ni/Pd, and (3) Ni/Pd/Au. These finishes are being targeted to replace the traditional HASL coating because the former systems leave a very flat layer over $\mathrm{Cu}$ that will not interfere with the placement and integrity of fine-pitch and ultra-fine-pitch, peripherally leaded packages and chip components.

The simplest of the three plating schemes is Pd alone. In this approach, the Pd serves as a protective finish over the $\mathrm{Cu}$; the $\mathrm{Pd}$ is consumed by the molten solder during the reflow process. The underlying $\mathrm{Cu}$ must be solderable or dewetting will occur once the molten solder contacts it. The Pd layer can be deposited by an electroless (autocatalytic) process so that unlimited thicknesses are theoretically possible. Typically, the deposit also contains a $6-7 \% \mathrm{P}$ content, the $\mathrm{P}$ being required as the reducing agent during the plating process. [51]. Thicknesses can range from as little as $0.15 \mu \mathrm{m}$ to as high as $1.5 \mu \mathrm{m}$; however, the typical value is between $0.25-0.51 \mu \mathrm{m}$ [52]. Within this thickness range, circuit board features show excellent solderability[53]. Thicker values of $0.4-0.5 \mu \mathrm{m}$ of Pd are preferred for thermosonic and thermocompression bondability [53]. Some studies indicate that $\mathrm{Au}$ ball bonding and $\mathrm{Al}$ wedge bonding may require an even thicker $\mathrm{Pd}$ layer[54].

Palladium coatings alone do not appear to offer the level of solderability protection required for circuit boards that are exposed to multiple reflow cycles (two-sided and/or mixed technology)[46]. Potential degradation mechanisms include $\mathrm{Cu}$ diffusion from the underlying conductor and arriving at the surface of the Pd layer to be subsequently oxidized, resulting in a degradation to solderability. (Evidence of this mechanism remains conflicting). As a second mechanism, Pd can develop an oxide layer which potentially inhibits wetting and spreading by the molten solder. In answer to this second scenario, a thin layer of immersion-deposited $\mathrm{Au}(0.05-0.2 \mu \mathrm{m})$ is deposited over the Pd to maintain adequate solderability when storage and processing conditions are too severe for the exposed Pd surface. This is the basis of the Ni/Pd/Au finish.

At present, the Ni/Pd finish is or particular interest for printed circuit board features. The addition of the Ni barrier layer assures that $\mathrm{Cu}$ migration will not take place through the Pd layer during elevated temperature excursions. The Ni layer becomes the solderable coating while the Pd still serves its role as the (sacrificial) protective finish. In some applications, additional layers may be present. For example, a Pd/Ni alloy layer may be deposited on the $\mathrm{Cu}$ base material prior to depositing the Ni solderable coating. The layer is very thin (termed a "strike" or "flash" layer), having a thickness of the order of $0.01 \mu \mathrm{m}[50]$. Electroless Ni layer thicknesses of $13-3.0 \mu \mathrm{m}$ as recommended by MIL- 
STD-1276D are typically used for Ni/Pd coatings in electronic applications. Thicker Ni layers of 2.5-5.0 $\mu \mathrm{m}$ can also be used, although they are not recommended for flex substrates due to their increased chances of failure by the brittle nature of the thicker $\mathrm{Ni}$ coating.

The Pd layer can have a wide range of thicknesses, from as low as $0.1 \mu \mathrm{m}$ to as high as $0.5 \mu \mathrm{m}[50,52,55]$. Palladium thicknesses exceeding $0.5 \mu \mathrm{m}$, and as high as 1.5 $\mu \mathrm{m}$ have been studied[52,55]. Nevertheless, Pd thicknesses in the range of 0.1-0.5 $\mu \mathrm{m}$ are sufficient to provide excellent solderability and shelf life. It was noted above that the Sn-based solders are susceptible to a loss in ductility as the Pd loading in them is increased. A sample computation of Pd content in solder was made for joints formed between $0.5 \mathrm{~mm}$ pitch (32 V/O) TSOP gull-wing leads and printed circuit board pads having 0.5, 1.0, and $1.5 \mu \mathrm{m}$ thick Pd layers[50]. A $50 \mu \mathrm{m}$ thick gap has been observed to exist between the lead and pad (Fig. 8). In the gap region (B), the Pd contents would be 1.4, 2.7, and $4.0 \%$, respectively. These values exceed the $1 \%$ benchmark mentioned earlier, above which, the potential for solder joint embrittlement becomes of concern. The potential quantity of dissolved Pd does not exceed the $1 \%$ level in the fillet regions (A) for any of the cases. Therefore, in order to maintain the Pd content below 1\%, the Pd thickness on the printed circuit board should not exceed approximately $0.35 \mu \mathrm{m}$ for this particular joint configuration; this is a value that is well within the preferred range of $0.1-0.5 \mu \mathrm{m}$ to support adequate solderability.

The issue of Pd embrittlement becomes particularly important for fine-pitch and ultra-fine pitch lead components when both the package leads and circuit board features may have the Pd protective finish on them.

The wetting and spreading process by molten solder on $\mathrm{N} / \mathrm{Pd}$ finishes (package $\mathrm{I} / \mathrm{O}$ or circuit board feature) requires first that the Pd layer have adequate solderability. Then, the Ni layer must have good solderability to support wetting by the molten solder once the $\mathrm{Pd}$ has fully dissolved into the solder. Generally speaking, the solderability of Ni/Pd finishes is not as good as that of $\mathrm{Sn}-\mathrm{Pb}$ solder finishes. However, they appear to be satisfactory for circuit board assembly processes. For example, wetting balance tests per ANSI/J-STD 002, Test E - "Wetting Balance Test (Leaded Components)" were performed on as-plated and aged TSOP leads ( 168 hours, $85^{\circ} \mathrm{C} / 85 \% \mathrm{RH}$ plus 500 thermal cycles between $-65^{\circ} \mathrm{C}$ and $\left.150^{\circ} \mathrm{C}\right)$ having either $\mathrm{Sn}-\mathrm{Pb}$ or $\mathrm{Ni}(1.2 \mu \mathrm{m}) / \mathrm{Pd}(0.1 \mu \mathrm{m})$ finishes[50]. A water-white rosin (R) flux could not successfully promote $\mathrm{Sn}-\mathrm{Pb}$ solder wetting and spreading activity over the Ni/Pd finish, even in the absense of any aging treatments. Rather, a stronger rosin-based, mildly activated (RMA) flux was required to provide the needed level of solderability for the as-coated samples. In addition, solderability was only 
acceptable for the aged samples when the RMA flux was used. A similar conclusion was drawn from both wetting balance and Ceramic Plate Solderability Tests of TQFP leads having the Ni/Pd plating layer[56].

The solderability of plated through-holes having a $\mathrm{Ni}(3.8 \mu \mathrm{m}) / \mathrm{Pd}(0.5 \mu \mathrm{m})$ finish was investigated using the wave soldering process[36]. Wave soldering provides a particularly sensitive evaluation of solderability because the wetting and spreading process takes place over a relatively short time period, typically 5-7 s, as opposed to $30-40 \mathrm{~s}$ for reflow processes. Defect analysis showed that the Ni/Pd finish had a comparatively greater number of unfilled holes and poorer wetting and spreading performance than did the other finishes (OSP, immersion Sn $(1.5 \mu \mathrm{m})$, and Ni $(3.8 \mu \mathrm{m}) / \mathrm{Au}(0.1 \mu \mathrm{m}))$. Any one of a number of aforementioned causes can be cited for the reduced solderability of the Ni/Pd finish, including surface contamination or oxidation as well as constitutional solidification of the solder as it became "loaded" with Pd. Also, the relatively slow rate of Pd metal dissolution may have reduced the speed of solder wetting and spreading to an extent that is revealed by an increased number of poorly formed joints for particularly "fast" soldering processes such as wave soldering as well as hand soldering.

Another aspect of the $\mathrm{Ni} / \mathrm{Pd}$ finish that might, at first, appear to only slow the wetting/spreading activity of the molten solder but, upon further investigation, can be seen to also pose a reliability concern, is the relatively slow dissolution-reaction between Pd and molten solder[58]. The consequence of a slow dissolution rate, besides the solder joint defects noted above, is that part of the Pd layer may be retained in the joint. In effect, the $\mathrm{Pd}$ coating becomes the solderable finish. Such a situation may provide an adequate joint structure in the as-fabricated condition. However, solid-state diffusion processes that are further accelerated at elevated service conditions can result in the further growth of the $\mathrm{PdSn}_{4}$ intermetallic layer at the solder/Pd interface. Once the $\mathrm{Pd}$ is fully consumed by the formation of the intermetallic compound layer, a bond must be established between the newly created $\mathrm{PdSn}_{4}$ layer and the underlying $\mathrm{Cu}$ (or other base metal) to support overall solder joint integrity. That bond may be expected to be marginal, at best, given the different crystal structures of the two materials and the fact that the intermetallic compound layer is growing towards that interface rather than develop from it. A lack of adhesion will jeopardize the reliability of the interconnect.

While the primary task of the Ni/Pd surface finish is to maintain solderability for assembly operations, it is also important to ascertain whether the finish has an impact on the reliability of the joints while they are in service. Experiments were performed by Johnson and co-workers which examined the electrical functionality and shear strength of 1206 chip resistor-on-FR 4 laminate solder joints that were subjected to thermal cycling (- 
$40^{\circ} \mathrm{C}, 125^{\circ} \mathrm{C}, 15 \mathrm{~min}$ holds, $5.5^{\circ} \mathrm{C} / \mathrm{min}$ ramps)[52]. Thin Pd layers $(0.25-0.30 \mu \mathrm{m})$ and thicker Pd layers $(0.46-0.51 \mu \mathrm{m})$ were evaluated after exposure of up to 4000 cycles. The electrical continuity of the joints remained for both Pd thicknesses. All of the solder joints exhibited a strength decrease with increased cycles. However, because a trend of similar magnitude was observed with HASL coated boards, the contributing factors of solder annealing and thermal fatigue damage likely caused the strength drop and would have probably overwhelmed any strength loss due to the Pd coatings. Also, the relatively large fillet volume (reduced $\mathrm{Pd}$ concentration) and large attachment area between the termination face and solder fillet would sustain mechanical integrity of the joint even if the gap region was embrittled by Pd content. In fact, statistically, there did no appear to be a significant difference in solder joint performance as a function of Pd thickness. Rather, the particular vendor and, as further study revealed, the extent of void formation in the joint from the time of manufacture, appeared to have a greater impact on any strength differences documented in the study.

A study was performed by Finley and co-workers which examined the reliability of $0.5 \mathrm{~mm}$ TSOP gull-wing lead/FR-4 printed circuit board solder joints that were exposed to 0,1068 , or 2417 thermal cycling conditions $\left(0^{\circ} \mathrm{C}, 100^{\circ} \mathrm{C}, 5 \mathrm{~min}\right.$ holds, $10^{\circ} \mathrm{C} / \mathrm{min}$ ramps). The thin $\mathrm{Ni} / \mathrm{Pd}$ coating $(0.1 \mu \mathrm{m})$ on the TSOP leads, alone, did not affect the lead pull strengths of the as-fabricated ( 0 cycles) solder joints when compared to joint made to leads and pads having the $\mathrm{Sn}-\mathrm{Pb}$ finish. Also, the added presence of printed circuit board $\mathrm{Ni} / \mathrm{Pd}$ finish (0.5-1.5 $\mu \mathrm{m}$ Pd thickness) likewise did not affect the pull strength of the leads in the as-fabricated condition ( 0 cycles). Besides describing the baseline conditions with either $\mathrm{Ni} / \mathrm{Pd}$ finish, these observations also ruled out concerns raised by a previous laboratory study which demonstrated the Ni-Sn intermetallic compound layer (that forms after the Pd layer has been dissolved away) to be somewhat more brittle than is the Cu-Sn layer that customarily forms between $\mathrm{Sn}-\mathrm{Pb}$ solders and the $\mathrm{Cu}$ pad, and may cause lower joint strengths when $\mathrm{Ni} / \mathrm{Pd}$ coatings are in use[59].

However, the Ni/Pd finish did cause a significant drop in the lead pull strength after thermal cycling. The strength values dropped from $2.0 \pm 0.3 \mathrm{lb}$. after 0 cycles (asfabricated) to $1.5 \pm 0.1 \mathrm{lb}$ (1068 cycles) and $1.2 \pm 0.1 \mathrm{lb}$ (2417 cycles). These strength drops were not observed with similarly cycled solder joints which either (1) did not have a $\mathrm{Ni} / \mathrm{Pd}$ finish on either the lead or Cu pad or (2) had only the thin Ni/Pd finish on the TSOP lead. These latter data rule out the possibility that the aforementioned strength drops were caused by a general relaxation of the strength of the solder due to the elevated temperature exposure. Palladium was detected as $\mathrm{PdSn}_{x}$ crystals in the joint gap of specimens with the $\mathrm{Ni} / \mathrm{Pd}$ finish on the circuit board. The PdSn $n_{x}$ crystals were absent from the joint fillets. 
Identification of the $\mathrm{PdSn} n_{x}$ crystals was made by scanning electron microscopy and energy dispersive $\mathrm{x}$-ray analyses. Unfortunately, these techniques were not sufficiently sensitive to confirm the $\mathrm{PdSn}_{\mathrm{x}}$ stoichiometry or to detect the presence (qualitatively or quantitatively) of elemental Pd dissolved in the solder of either region.

Pull strength tests were performed on solder joints that were made between $0.5 \mathrm{~mm}$ TQFP leads and printed circuit board pads coated with either $\mathrm{Sn}-\mathrm{Pb}$ solder or a Ni/Pd finish[56]. Coating thicknesses were not given. Although the strengths of the two variations of solder joints were equivalent, the joints made to $\mathrm{Ni} / \mathrm{Pd}$ coated pads exhibited significantly less ductility in the load-displacement curves than did the joints made to $\mathrm{Sn}-\mathrm{Pb}$ coated boards. The morphology of the fracture surfaces also indicated reduced ductility in joints made to the $\mathrm{Ni} / \mathrm{Pd}$ finish.

The third coating scheme involves the addition of a Au flash to the surface of the Pd layer. The Au coating is usually deposited from an immersion bath to a thickness of 0.05 $0.2 \mu \mathrm{m}$. The Au flash is added so as to limit any oxidation of the Pd surface that may contribute to an increased variability or general deterioration of its solderability.

In conclusion, studies of the $\mathrm{Ni} / \mathrm{Pd}$ finish indicate the following general points: (1) The preferred thicknesses of the $\mathrm{Ni}$ and Pd layers are 1.3-3.0 $\mu \mathrm{m}$ and 0.25-0.51 $\mu \mathrm{m}$, respectively. (2) The solderability of the Ni/Pd finish will be slightly poorer than that of $\mathrm{Sn}-\mathrm{Pb}$ or $\mathrm{Au}-\mathrm{Ni}$ coatings. This difference will be particularly poignant in relatively rapid soldering processes such as hand and wave soldering. The addition of an immersion $\mathrm{Au}$ strike $(0.05-0.2 \mu \mathrm{m})$ on the surface of the Pd layer will likely alleviate any inconsistent solderability behavior. Also, the solder joints fillets will exhibit some graininess, the degree of which increases with increase Pd thickness. (3) The extent of Pd contamination in the smallest volume of the joint, typically the gap between the printed circuit board pad and the package $\mathrm{V} / \mathrm{O}$, should remain below approximately $1 \%$ when surfaces having a $\mathrm{Ni} / \mathrm{Pd}$ finish are in use. Thermal cycling of the solder joints made to Ni/Pd finishes can potentially degrade its monotonic strength, depending upon the quantity of Pd present in the solder upon solidification. This aspect of solder joint reliability should be thoroughly documented for the projected service conditions.

\section{Ag finish}

Although relatively new to printed circuit board electronics assembly, $\mathrm{Ag}$ (final) finishes have been used extensively to support solder processes in the past. The MILSTD-1276D cites two recommendations for Ag finishes: (1) Type I, Grade B, 3.8-8.9 $\mu \mathrm{m}$ thick and (2) Type I, matte (non-brightened), 3.9-8.9 $\mu \mathrm{m}$ thick. An important advantage of the use of $\mathrm{Ag}$ as opposed to the $\mathrm{Au}$ and/or Pd containing coatings is clearly a lower material 
cost. However, the use of Ag coatings in electronics applications has always been met with some trepidation due to a concern for Ag electromigration. Silver electromigration is the tendency for $\mathrm{Ag}$ (and other metals) to oxidize at the anode and redeposit at the cathode (via the opposite reduction reaction ) in the presence of a liquid and a voltage potential. The re-deposited $\mathrm{Ag}$ grows into a filament of material stretching between the two electrodes. Once the filament has grown completely across the gap, it shorts the two electrodes, resulting in a signal disturbance in the electronics or, worse yet, physical damage to the circuitry. Although a number of studies have examined $\mathrm{Ag}$ migration from thick film compositions and electroplated $\mathrm{Ag}$ coatings, there is no data indicating $\mathrm{Ag}$ migration from immersion Ag coatings, the primary coating technique used on printed circuit boards.

Silver does not have the same noble properties as do $\mathrm{Au}$ or even $\mathrm{Pd}$. For example, $\mathrm{Ag}$ does readily oxidize into $\mathrm{Ag}_{2} \mathrm{O}$. Interestingly enough, though, $\mathrm{Ag}_{2} \mathrm{O}$ also reduces to $\mathrm{Ag}$ metal and $\mathrm{O}_{2}$ in an air atmosphere when heated to temperatures in excess of $190^{\circ} \mathrm{C}[60]$. However, the customary dark tarnish that forms on $\mathrm{Ag}$ coatings is largely the result of sulfidation, not oxidation; the surface layer that forms is $\mathrm{Ag}_{2} \mathrm{~S}$. Like an oxide film, the sulfide layer can also degrade the coating's solderability as it becomes thicker.

Functionally, the Ag coating acts as a (sacrificial) protective finish, the same as would $\mathrm{Au}$ or Pd. In the initial stages of the soldering process, the molten solder must wet and spread over the $\mathrm{Ag}$ coating. Therefore, the $\mathrm{Ag}$ surface must be solderable. The $\mathrm{Ag}$ layer then begins to dissolve into the molten solder; the $\mathrm{Ag}$ coating does not melt; the melting temperature of $\mathrm{Ag}$ is $961^{\circ} \mathrm{C}$. Once the $\mathrm{Ag}$ layer is completely dissolved, the molten solder then wets to the underlying base metal surface, usually $\mathrm{Cu}$. Although $\mathrm{Ag}$ and $\mathrm{Au}$ have similar physical metallurgies with respect to $\mathrm{Sn}$ and $\mathrm{Sn}-\mathrm{Pb}$ solders, a difference that may become important in some cases is the fact that $\mathrm{Ag}$ dissolves into $\mathrm{Sn}-\mathrm{Pb}$ solder at a rate that is approximately one-third as fast as is that of $\mathrm{Au}$ (though still considerably faster than either $\mathrm{Pd}$ or $\mathrm{Cu}$ )[58]. Therefore, as described earlier, relatively rapid soldering processes (for example, hand soldering and wave soldering) may result in incomplete dissolution of the $\mathrm{Ag}$ layer. In effect, the $\mathrm{Ag}$ coating becomes the solderable finish, rather than the underlying base metal $(\mathrm{Cu})$. This situation may be tolerable with regards to the integrity of the interconnect with the following exception: Solid-state diffusion processes caused by elevated temperature service conditions can result in the accelerated growth of $\mathrm{Ag}_{3} \mathrm{Sn}$ intermetallic layer at the interface. The growth kinetics for electroplated $60 \mathrm{Sn}-40 \mathrm{~Pb}$ coatings on wrought $\mathrm{Ag}$ are described by equation (7) below for the temperature range of $25^{\circ} \mathrm{C}$ to $170^{\circ} \mathrm{C}$. The data, which were obtained from Reference [61], were used by the author to calculate the equation parameters by multivariable, linear regression analysis. 
where $\mathrm{x}$ is the layer thickness in meters (m); $\mathrm{x}_{\mathrm{o}}$ is the initial layer thickness $(\mathrm{m})$ which is equal to $0 ; t$ is the time in seconds (s); and $\mathrm{T}$ is the temperature in Celsius $\left({ }^{\circ} \mathrm{C}\right)$. Assuming a density of $9 \mathrm{~g} / \mathrm{cm}^{3}$ for the $\mathrm{Ag}_{3} \mathrm{Sn}$ layer, then the formation of each unit thickness of $\mathrm{Ag}_{3} \mathrm{Sn}$ will consume 0.63 unit thicknesses of $\mathrm{Ag}$ and 0.33 unit thickness of $\mathrm{Sn}$. Once the $\mathrm{Ag}$ is fully consumed by such growth, the mechanical integrity of the joint becomes dependent upon a bond, if any, that develops between the brittle $\mathrm{Ag}_{3} \mathrm{Sn}$ intermetallic compound layer and the underlying $\mathrm{Cu}$ (Fig. 4). Although data pertaining to a $\mathrm{Ag}_{3} \mathrm{Sn} / \mathrm{Cu}$ bond does not as yet exist, it can be surmised that adhesion between such dramatically different crystal structures and material chemistries would be marginal, at best, especially since the $\mathrm{Ag}_{3} \mathrm{Sn}$ layer is growing towards the $\mathrm{Cu}$. If the $\mathrm{Ag}_{3} \mathrm{Sn}$ were growing from the $\mathrm{Ag} / \mathrm{Cu}$ interface, there is a chance that some epitaxial relationship between the $\mathrm{Ag}_{3} \mathrm{Sn}$ layer and $\mathrm{Cu}$ would provide a measure of adhesion.

Silver finishes for printed circuit boards are deposited by an immersion process. Preferred layer thicknesses range from $0.10-0.15 \mu \mathrm{m}[46]$. Thicknesses of $0.04 \mu \mathrm{m}$ or below do not provide adequate solderability protection[62]. As noted above, $\mathrm{Ag}$ finishes are sensitive to tarnish formation. Therefore, the immersion plating baths typically contain an organic inhibitor that co-deposits with the Ag to protect the finish surface.

Solderability data have been reported in the literature with generally very positive results. The ITRU/October project reported excellent solderability protection is offered by the Ag coatings for both surface mount and through-hole circuit boards[46]. Also, the $\mathrm{Ag}$ coatings protected the $\mathrm{Cu}$ feature solderability during multiple passes through a reflow oven. Similar observations were made from the results of both laboratory meniscograph tests on $\mathrm{Ag}$-plated $\mathrm{Cu}$ coupons as well as from circuit board test vehicle using no-clean fluxes[63]. An extensive solderability study of surface finishes with immersion Ag being amongst the candidate chemistries, was reported upon by Iman and Koon[64]. The immersion Ag coated circuit boards were evaluated for solderability, using wetting balance and area-of-spread metrics. The immersion Ag finish outperformed all other candidate, alternative finishes (e.g., OSP's, immersion $\mathrm{Au}$, immersion $\mathrm{Pd}$, etc.) for solderability in both air and nitrogen reflow processes. A pre-bake of the boards $\left(8\right.$ hours, $\left.105^{\circ} \mathrm{C}\right)$ did not appear to degrade that solderability. The $\mathrm{Ag}$ finish worked well with both no-clean or water-soluble fluxes.

Excellent lead (SOIC) pull strengths were observed for solder joints in the asfabricated condition[46]. However, because $\mathrm{Ag}$ finishes are a relatively recent development in circuit board finishes, there is only a limited amount of reliability data for solder joints 
made to the $\mathrm{Ag}$ coated features. Surface mount test vehicles (FR-4 laminate) that contained a variety of chip components as well as leadless ceramic chip carriers (LCCC), have undergone thermal cycling exposure $\left(-55^{\circ} \mathrm{C}, 125^{\circ} \mathrm{C}, 30 \mathrm{~min}\right.$ holds, $\left.6^{\circ} \mathrm{C} / \mathrm{min}\right)[62]$. The reliability of the LCCC's attached to Ag-coated circuit boards has been comparable that of HASL coated boards. Similar trends appear to be developing in a reliability study at Auburn University[52].

\section{Barrier finishes}

It was noted above that a $\mathrm{Ni}$ layer was interposed between the $\mathrm{Pd}$ finish and the $\mathrm{Cu}$ circuit board feature to serve as a barrier layer against potential $\mathrm{Cu}$ diffusion into and through the Pd layer and to the Pd layer surface, where it could oxidize and thereby degrade solderability. (The Ni barrier layer then serves as the solderable finish for the soldering operation.) The need for a barrier layer can be generalized for a number of circumstances. Besides storage conditions, additional processing steps performed on the circuit board (e.g., multiple reflow steps prior to a pad or board side being soldered) or exposure to elevated temperature environments prior to, and after soldering operations, may require the presence of a barrier layer to prevent mutual reactions between the different metals that may potentially degrade surface solderability and/or solder joint reliability later on.

The circumstances requiring consideration of a barrier layer are discussed. For example, some applications of soldered electronics include very high temperature environments. Automobile underhood electronics and down-hole, oil drilling electronics represent applications in which service temperatures can exceed $150-200^{\circ} \mathrm{C}$ for long operational periods of time. A consequence of long-term exposure by soldered joints to elevated temperatures is the accelerated growth of an intermetallic compound layer between the solder and $\mathrm{Cu}$ base metal via solid-state diffusion processes. The developing, brittle intermetallic compound layer can not only degrade the mechanical integrity of the joint under load, but it also results in the consumption of the solder and base material that may jeopardize the functionality of the joint, particularly those joints made with very thin adaptations of the two material fields. Intermetallic compound layer growth can be curtailed by adding a barrier layer on top of the $\mathrm{Cu}$ layer, to isolate it from the solder. Nickel and $\mathrm{Fe}$ are two such candidate layers that can limit solid-state intermetallic compound layer growth between $\mathrm{Cu}$ and $\mathrm{Sn}$-based solders[65].

Also, barrier layers can have an important role during the soldering process. Applications may arise in which the circuit board soldering process exposes the base metal to molten solder at higher-than-normal temperature or for an inordinately long period of 
time. Or, a soldered joint may be reflowed a number of times, such as during component replacement exercises when prototyping a new product. Contact between the molten solder and the base metal causes dissolution of the latter. The base material can potentially be completely consumed by prolonged exposure to molten solder, particularly when it is present as a relatively thin section of foil or as a coating (e.g., the solderable coating). Therefore, a barrier layer (again, $\mathrm{Ni}$ and $\mathrm{Fe}$ are good candidates) is placed over the $\mathrm{Cu}$ to serve as the solderable finish that will contact the molten solder under these harsh process condition. Data presented in Reference [58] can provide relative rates of dissolution of several metals in molten solder.

\section{Thickness measurement techniques.}

Irrespective of the finish system that is selected for a particular application, it is critical that assurances be made that the individual layers are deposited with the correct thicknesses. The most accurate method of determining film thicknesses is to perform metallographic cross-sections on representative samples. A scanning electron microscope (SEM) is then used to accurately determine the thicknesses of the various layers by direct measurement from photographs. This technique can be used to measure layer thicknesses as small as approximately $0.1 \mu \mathrm{m}$.

However, the metallographic cross-section approach is rather time consuming. A faster technique which is also acceptable for quality control, particularly on the shop floor, is that of X-ray fluorescence (XRF) $[66,67]$. This procedure is also called the betabackscattering technique. By this procedure, an $\mathrm{x}$-ray beam is directed onto the coating, normal to its surface. A counter/detector measures the wavelength and, quantity of $x$-rays per each wavelength, that are scattered directly back from the coating. Having knowledge of which $\mathrm{x}$-ray wavelength is characteristic of each of the individual layer composition, and with calibration standards of $\mathrm{x}$-ray intensity versus thickness, the "backscattered" $\mathrm{x}$-rays can be used to compute the thicknesses of each of the individual layers. The XRF apparatus can discriminate between different layer composition as long as the elements in the layers are approximately four spaces apart on the Periodic table. Also, as the layers become thicker, the backscattered $\mathrm{x}$-rays are attenuated as they pass through coatings on top of the originating layer. Therefore, multi-layer standards are often used to improve the accuracy of the system calibration.

\section{Impact of Coating Behavior on Solder Joint Performance}

The primary objective of surfaces finishes is to provide adequate solderability of the base material up to, and during, the soldering process. However, it is also important to 
understand the structure of the interconnect after the solder has solidified. This aspect becomes particularly important in the event that failure analysis must be performed on a defective solder joint. Shown in Fig. 9 is a schematic diagram of the solder joint resulting from the use of a solderable layer (and initially present protective layer). The joint structure is comprised of: (1) the base material, (2) the base material/solderable finish interface, (3) the solderable layer, (4) the solderable layer/solder interface which includes the intermetallic compound formed there, and lastly (5) the solder layer. Each of these features, with the probable exception of the base material, is a potential site of mechanical failure. Whether fracture takes place in the solder, within the intermetallic compound layer, or at one to the two interfaces will depend upon the strengths of the solder and intermetallic compound layer, the maximum load, and the rate at which that load is impressed upon the joint $[59,68,69]$.

The strength of the solderable layer, itself, is not usually a factor in the overall integrity of the joint; however, there is one situation worth noting. Often times, electroplated layers may be formed in multiple depositions, resulting in the layer actually being comprised of very thin sub-layers. This phenomenon may occur when the plating process is interrupt, or when electroplating is performed using the "barrel" plating process. As a consequence, the layer can exhibit delamination at the sub-layer boundaries in the event that they did not adhere to one-another. This defect can result in catastrophic failure of the joint as a whole.

Lastly, adequate adhesion must exist at the base material/solderable layer interface. The bond between the two materials must survive the elevated temperatures of one or more soldering cycles as well as be unaffected any post-assembly heat environments (e.g., thermal cycling, thermal shock, or "burn-in" testing) to provide for a reliable interconnect during service. Should such interfaces be suspect as the source of a particular failure, then the plating process used to deposit the solderable finish must be closely examined for faults.

\section{Surface Finish Compatibility with Other Circuit Board Assembly Processes and Materials}

Finally, it is important to realize that the finishes selected for package I/O's or for the conductive features on circuit boards must accommodate several other assembly processes and materials. An important consideration for alternative finishes is their compatibility with wire bonding techniques. This issue is of particular importance as chipon-board and chip-on-flex assemblies become an increasingly more popular packaging option. The interconnect between the chip and the circuit board is often made using 
thermocompression ball bonding or thermosonic (stitch) bonding procedures. In addition to compatibility with other bonding techniques, the coating may be required to accommodate other joining materials such as non- $\mathrm{Sn}-\mathrm{Pb}$ solder compositions and conductive adhesives as well as provided adequate adhesion to conformal coatings. Each of these aspects will be briefly described below.

Wire Bonding. In a growing number of applications, the surface finish of a lead frame or circuit board pad must accommodate wire bonding operations. Wire bonding generally describes one of two specific processes: (1) thermocompression ball bonding and (2) thermosonic wedge or stitch bonding. From the viewpoint of surface finishes, wire bonding differs from a soldering operation because the joint is made to the top most layer of the coating. Therefore, the condition of the protective layer's surface is of much greater consequence to wire bond processes. Nevertheless, the immediate, underlying layer (solderable layer or base material) may also affect the realization of a good bond at the time of assembly and the reliability of that bond while the part is in service. Some surface finishes are not acceptable for wire bonding processes. Coatings of $\mathrm{Sn}-\mathrm{Pb}$ solder, other solder compositions, and $\mathrm{Sn}$, whether hot-solder dipped, plated, or plated-and-fused will not provide an acceptable surface for wire bonding. These soft coatings will absorb the deformation required to form the ball or stitch and develop the metallurgical bond between the ball/stitch bond structures and coatings. In addition, the bonding between Au ball or stitch bond structures and $\mathrm{Sn}$ or $\mathrm{Sn}$-based solders raises the issue of Au-Sn intermetallic compound layer formation by solid-state diffusion processes at elevated service temperature service. A significant portion of the bond can be quickly converted to intermetallic compound due to its small size, causing a loss of electrical continuity.

Wire bonding processes cannot be performed on OSP coated surfaces. The organic material comprising the OSP layer would prevent the required metallurgical bond from being formed between the $\mathrm{Au}$ wire and underlying $\mathrm{Cu}$ surface.

The inability to wire bond to OSP-coated surfaces illustrates an important aspect of this interconnect technique. That is, organic surface contaminants are probably the single most prevalent cause of poor wire bonds. Studies have clearly shown the detrimental effects that such contaminants have on the bonding processes [70,71]. Organic films in excess of $0.1 \mathrm{~nm}$ can severely degrade the bondability of metallic finish surfaces[72]. Organic contaminants can arise, not only from the storage environment and poor handling practices, but may also accumulate in the coating by their co-deposition with the metal component from the plating bath.

A survey of the wire bondability of the $\mathrm{Ni} / \mathrm{Au}, \mathrm{Ni} / \mathrm{Pd}, \mathrm{Ni} / \mathrm{Pd} / \mathrm{Au}$, and $\mathrm{Ag}$ finishes will be made, beginning with the Ni/Au finish. The Ni/Au finish has proven very 
successful for wire bonding practices. Recall that the initial Ni layer is deposited by electroless (autocatalytic) plating from a bath containing 6-8\% $\mathrm{P}$ that serves as the reducing agent. The Au layer can be deposited by either an electroless (autocatalytic) process similar to electroless $\mathrm{Ni}$ deposition (including the co-deposition of reducing agents) or through the use of a immersion (conversion) coating. Electroless Au coatings range in thickness from 0.5-2.0 $\mu \mathrm{m}$ while immersion Au coatings are limited to thicknesses of 0.05-0.2 $\mu \mathrm{m}$. The immersion Au processes have become more popular, since the layers are generally more free of co-deposited organic compounds and less material is required to maintain the same level of protection, thus reducing process costs.

Aside from solderability protection issues, the Au thickness also determines whether the underlying Ni layer will have an affect on the wire bonding process. For example, it has been observed that $\mathrm{Al}$ wire bonding can be successfully performed to electroless $\mathrm{Ni} /$ immersion Au coatings. However, the actual metallurgical bond appears to be formed between the $\mathrm{Al}$ ball and the underlying Ni layer [53]. In this case, the thinner $\mathrm{Au}$ layer may be preferred in order that it does not interfere with the Al-Ni interaction.

A different situation exits with Au wire bonding. That is because the bonding metallurgy develops between the Au wire (soon to be ball or wedge) and the Au finish. Gold wire bonding can also be performed on immersion Au over an electroless Ni finish. However, the bond strengths tend to be slightly lower and exhibit a greater degree of variability than do those made to thicker electroplated or electroless Au coatings[73]. A greater effort towards process control for both the immersion Au thickness as well as the selected bonding parameters is required to optimize bond yields. Thus, thicker Au finishes (electroless $\mathrm{Au}$ ) are preferred for the final layer when Au ball bonding processes are to be performed. Because the Au wire bond is actually made to the Au layer, the Ni underlayer may not be necessary, should other soldering processes and the unlikely occurrence of $\mathrm{Cu}$ $\mathrm{Au}$ interdiffusion processes so warrant.

The wire bondability of $\mathrm{Ni} / \mathrm{Pd}$ and $\mathrm{Ni} / \mathrm{Pd} / \mathrm{Au}$ finishes is now discussed. Variable results have been observed with $\mathrm{Al}$ wire bonds to Ni/Pd coatings. Satisfactory $\mathrm{Al}$ wire bondability has been realized with an electroless layer of Pd, $0.15-0.25 \mu \mathrm{m}$, over $\mathrm{Ni}$ and a flash of $\mathrm{Au}$ on the Pd surface [53]. A thicker Pd finish $(0.25-0.64 \mu \mathrm{m})$ is recommended for Au wire bonding processes; these Pd thickness levels can be realized with immersion processes but are more readily obtained with electroless Pd platings. The fact that the $\mathrm{Au}$ wire bond is made to the Pd layer suggests that an underlying Ni layer can be omitted for strictly wire bonding function, when all other factors (e.g., the need for a barrier layer) are taken into account. 
Finally, an immersion Au strike is sometimes added on the surface of the Pd layer. The Au layer improves the $\mathrm{Au}$ wire bondability of the $\mathrm{Pd}$ surface by limiting oxide formation that can interfere with the bonding process. Along these lines, the NCMS Surface Finishes Study reported poor Al wire bonding results on Pd coatings of thicknesses from $0.2 \mu \mathrm{m}$ to $0.9 \mu \mathrm{m}$ [73]. However, satisfactory strengths were obtained, once a $0.2 \mu \mathrm{m}$ Au strike had been added over the Pd layer. An important observation from the work in Reference [73] is that the pull strength results varied amongst different vendor sites at which the bonding and strength measurements were performed. This observation suggests that the Ni/Pd plating methodologies are very sensitive to a particular process and operator. Moreover, because that sensitivity is reflected in the wire bonding data, the process variability is likely affecting the condition of the exposed Pd surface.

A study of Au ball bondability, Au wedge bonding, and $\mathrm{Al}$ wedge bonding was performed by Hillman, et al[54]. Only the Au wedge bond was successful on electroless $\mathrm{Pd}$ plated directly over $\mathrm{Cu}$; however, all three techniques produced satisfactory to very good results when a Au strike was added to the exposed Pd surface. It can only be inferred that the poor bondability of $\mathrm{Pd}$ on $\mathrm{Cu}$ was due to either a contaminated, as-plated $\mathrm{Pd}$ surface or that $\mathrm{Pd}-\mathrm{Cu}$ interdiffusion had occurred which resulted in $\mathrm{Cu}$ reaching the (electroless) Pd surface under storage. The addition of the Au strike to the Ni/Pd finish over $\mathrm{Cu}$ also improved an already satisfactory bondability exhibited by all three techniques on the Ni/Pd stack. On the other hand, Au wire bonding has been successfully performed on Pd coatings over component (leaded) I/O's in the absense of a Au layer[49].

The wire bondability data of $\mathrm{Pd}$ and $\mathrm{Ni} / \mathrm{Pd}$ finishes appeared to exhibit variable results between different studies. As suggested earlier by results from one investigation, these differences likely arise from inconsistent plating processes that manifest themselves in variations in the Pd surface condition. By virtue of the sensitivity of wire bonding to surface condition, bondability data reflect upon those process variabilities. Based upon this premise as well as the cited data, the addition of the thin Au "flash" layer appears to improve both the magnitude and repeatability of bond strengths made to the underlying $\mathrm{Ni} / \mathrm{Pd}$ finish and may prove to be a necessary step for using Ni/Pd finishes for wire bonding applications.

Lastly, test results are being published on the wire bonding performance of immersion he $\mathrm{Ag}$ fines. Pull strengths of $\mathrm{Al}$ wire bonds were very good in the asfabricated condition and remained so after exposure of the coating to $150^{\circ} \mathrm{C}, 1$ hour, air conditions or $150^{\circ} \mathrm{C}, 1$ hour $+275^{\circ} \mathrm{C}, 9 \mathrm{~min}$. A slight increase in data scatter was observed with increasingly severity of these pre-condition treatments[62]. Likewise, the Au wire bondability proved to be very good on the $\mathrm{Ag}$ surfaces. Hillman, et al reported excellent 
bonding strength on $\mathrm{Ag}$ finishes for all three bond process (Au wedge, $\mathrm{Au}$ ball, and $\mathrm{Al}$ wedge)[54]. Data is still being compiled for the wire bondability of immersion Ag coating. A precautionary note is made with regards to the nature $\mathrm{Ag}$ to tarnish under prolonged exposure to the environment and the potential effect that the tarnish layer has on wire bondability. Resulting contamination effects may not appear, at first, as a drop in bond strength (mean). Rather, initial indications of surface contamination effects may be manifested by an increased variability (standard deviation) in the strength data.

\section{Conductive Adhesives and Conformal Coatings}

The use of conductive, organic adhesives as a replacement for traditional solders presents unique requirements for the finishes used on circuit board features and package I/O's. In a similar regard, the adhesion behavior of conformal coatings must be compatible with those finishes. First, the case of conductive adhesives will be examined. Clearly, a loss of adhesion between the conductive adhesive compound and the surface finish will culminate in a loss of electrical and mechanical functionality for the interconnect. It can be safely assumed that, at the present time, component suppliers and circuit board manufacturers provide product finishes that are suitable for solder assembly. Therefore, a "reactive" approach must be taken to determine the compatibility of a particular adhesive compound with currently available surface finishes such as OSP's, Ni-Au, Ni-Pd, and Ag. Of course, the preferred approach is to identify a surface finish that optimizes performance of the conductive adhesive and specify it for the component I/O or circuit board finish.

Besides the intrinsic adhesion properties between the adhesive and finish, the cleanliness of the surface finish will strongly impact adhesion. Therefore, it is critical that residues from the plating bath(s) or handling operations be thoroughly removed from the bond pad or component $\mathrm{I} / \mathrm{O}$ prior to the dispensing of the adhesive on them.

Excellent adhesion is also required between conformal coatings and the surface finish circuit board features and package I/O's. Should such adhesion deteriorate to the extent that there is separation between the materials, a continuous path may develop that allows the entry and transport of contaminants to exposed metal features and solder joints. The result will be an increased likelihood of conductor and solder joint corrosion that culminates into a loss of solder joint, component, and system reliability. Unfortunately, because conductive features represent such a small percentage of the circuit board real estate, adhesion between them (and their finish) and conformal coatings is not always wellstudied. Rather, bonding properties investigation have concentrated largely on the interface between coating and the circuit board laminate, solder mask if present, or the device package. As in the case of conductive adhesives, it is to be expected that a primary source 
of poor adhesion between the conformal coating and the surface finish will be contamination of the latter. Contaminant films, such as those resulting from pull-out from plating baths or poor handling practices, must be removed prior to the application of the coating.

\section{Alternative Solders}

An important facet of surface finishes is their role in allowing the use of alternative solder compositions for circuit board assembly. This point has recently received increased attention as $\mathrm{Pb}$-free solder technology has made in-roads into electronic assemblies. The foremost reason that surface finishes have such an important role in alternative solders is that the manufacturability and reliability properties of new solder compositions can be negatively impacted by their contamination with $\mathrm{Pb}$ that is present in HASL or $\mathrm{Sn}-\mathrm{Pb}$ electroplated coatings. For example, the addition of $\mathrm{Pb}$ to a number of alloy compositions reduces the solidus temperature of those solders, thus reducing their maximum service temperatures[74]. The formation of lower melting temperature, higher order (ternary, quaternary, etc.) phases can also occur when $\mathrm{Pb}$ contaminates the solder. These phases are the last to solidify and therefore, have a tendency to do so along grain and phase boundaries. This morphology results in easy pathways for crack propagation that will compromise the mechanical integrity of the joint. For instance, when $\mathrm{Pb}$ is added to solders containing both $\mathrm{Sn}$ and $\mathrm{Bi}$, the $8 \mathrm{Sn}-40 \mathrm{Bi}-52 \mathrm{~Pb}$ ternary eutectic phase may develop that has a solidus temperature of $95^{\circ} \mathrm{C}[75]$. This phase may be responsible for a strength loss when $\mathrm{Sn}$ and $\mathrm{Bi}$ containing solders are contaminated with $\mathrm{Pb}$.

Each of the coatings cited above has been exercised in one or more studies on $\mathrm{Pb}$ free solders, with the exception of the $\mathrm{Ag}$ finish (which is largely a timing issue at this time and certainly not a technology-based decision). However, alternative finishes cannot simply be called-out as drop-in replacements for $\mathrm{Sn}-\mathrm{Pb}$ coatings when alternative solders are targeted for use. There is a synergistic relationship between the finish and solder composition. That interrelationship culminates into two important areas: (1) the process parameters required to assemble with the non-Sn- $\mathrm{Pb}$ solder and (2) the reliability of the solder joints made between the selected finish and alternative solder alloy. Addressing point (1), the surface finish must accommodate higher or lower process temperatures that are geared to the melting properties of the alternative solder. For example, early concerns were raised as to whether OSP coatings could survive long enough to allow reflow soldering of higher melting temperature, $\mathrm{Sn}$-based solders (e.g., $96.5 \mathrm{Sn}-3.5 \mathrm{Ag}$ alloy having a eutectic temperature of $221^{\circ} \mathrm{C}$ ). Moreover, double-sided circuit boards would require the OSP to provide suitable protection for two reflow cycles. It was demonstrated 
that imidazole-based, OSP coatings could survive, not only one, but also two such reflow cycles when performed under a $\mathrm{N}_{2}$ atmosphere, and still maintain adequate solderability $[34,35,37]$. The results were not as promising when a single reflow cycle was performed in air[76]. Immersion $\mathrm{Sn}$ and $\mathrm{Ni} / \mathrm{Pd}$ coatings also provided adequate solderability with the use of the higher temperature solders, including the reflow soldering of surface mount product as well as the wave and hand soldering of through-hole circuit boards[36,37,77].

On the other hand, the lower melting temperature $\mathrm{Pb}$-free alloys (e.g., 58Bi-42Sn with a eutectic temperature of $139^{\circ} \mathrm{C}$ or $52 \mathrm{In}-48 \mathrm{Sn}$ with a eutectic temperature of $118^{\circ} \mathrm{C}$ ) present a different set of potential difficulties. OSP coatings tend to dissipate from the $\mathrm{Cu}$ surface at temperatures of approximately $120^{\circ} \mathrm{C}$ to $150^{\circ} \mathrm{C}$ so as to allow the molten solder to wet and spread over that surface. Thus, with very low melting temperature solders, the OSP coating may fail to completely dissipate. As a result, the coating will appear to be an organic contaminant and the molten solder will poorly wet and spread over the surface. In a similar light, dissolution processes that remove the noble metal protective finish during soldering are slowed at lower processing temperatures. If too sluggish, the protective finish may not be completely dissolved into the solder. As a result, the joint is formed between the solder and the protective finish rather than between the solder and the underlying solderable finish. This situation can pose a reliability concern latter on for the following reasons: (1) The mechanical integrity of the retained protective layer/solderable layer interface may not be able to survive the service conditions, particularly with the solder joint present over it. (2) The intermetallic compound layer formed between the solder and protective finish may be structurally weak and thus, compromise the joint integrity. (3) Complete consumption of the remaining protective finish later on through solid-state intermetallic compound layer growth will result in an interface being formed between that intermetallic compound layer and the solderable layer (Fig. 4). The strength of such interfaces are largely undocumented and in all likelihood, not expected to be very robust due to the unmatched crystal structures. Therefore, it may be necessary to raise the process temperatures in order to realize complete dissolution of the protective finish, thereby losing some of the advantages of a low temperature solder. As a benchmark, prototype surface mount test vehicles having either OSP or immersion Sn coatings have been successfully assembled with the 58Bi-42Sn solder using a $\mathrm{N}_{2}$ reflow process[37].

The second concern (2) arising from the use the variety of surface finishes with alternative solder compositions is the coating's impact on solder joint reliability. Specifically, it must be documented as to the effect had by the finish coating, after it has dissolved into the solder, on the latter's mechanical properties. For example, the role of $\mathrm{Au}$ 
contents in excess of 3-4 wt\% on the embrittlement of $\mathrm{Sn}-\mathrm{Pb}$ solder were discussed earlier. Similar analyses have been performed on several other solder compositions[78]. The authors of Reference [78] predicted $\mathrm{Au}-\mathrm{Sn}$ intermetallic particle formation (as a precursor to embrittlement) in $100 \mathrm{Sn}$ and $96 \mathrm{Sn}-4 \mathrm{Ag}$ solders at approximately $10 \%$ loading with $\mathrm{Au}$. The low-temperature $58 \mathrm{Bi}-42 \mathrm{Sn}$ solder was affected by only $0.8 \%$ Au contamination. The 50In-50Sn was not significantly affected by Au additions.

Unfortunately, only a very limited amount of fundamental work has been done on the effects of Pd content on the mechanical properties of $63 \mathrm{Sn}-37 \mathrm{~Pb}$ solder[48]. The author is unaware of such work on alternative alloys. However, several circuit board test vehicle investigations have been conducted that provide valuable data. A study was made of prototype, surface mount circuit boards having OSP or Ni-Pd finishes; the test vehicles were assembled with $96.5 \mathrm{Sn}-3.5 \mathrm{Ag}$ alloy (eutectic temperature equal to $221^{\circ} \mathrm{C}$ ) and a highstrength, $91.84 \mathrm{Sn}-3.33 \mathrm{Ag}-4.83 \mathrm{Bi}$ solder (onset temperature of $212^{\circ} \mathrm{C}$ ) [79]. Shear test measurements on chip capacitors clearly showed a significant strength drop after thermal cycling that was associated with the Ni/Pd finish and specifically attributed to an effect by Pd content in the solder. In another study, tests of $256 \mathrm{PQFP}(0.4 \mathrm{~mm}$ pitch) joints and $0.5 \mathrm{~mm}$ pitch $20 \mathrm{I} / \mathrm{O}$ SOIC joints made to Ni/Pd finish using $\mathrm{Sn}$ - $\mathrm{Ag}$-Cu solder showed significant strength decreases after exposure of the test vehicles to 2500 and 5000 thermal cycles $\left(0^{\circ} \mathrm{C}, 100^{\circ} \mathrm{C}, 3\right.$ hours/cycle). The strength drops were not observed with either $\mathrm{Sn}$ or $\mathrm{Sn}-\mathrm{Pb}$ finishes after the same thermal cycling experiments[80]. The presence of $\mathrm{PdSn}_{4}$ crystals was confirmed in the solder material comprising the joints. Of course, it must be noted that the retained strength levels may have still been adequate for the application, a point that must be considered for each specific case.

Finally, a large extent of the above discussion has centered upon the circuit board finish. The surface finish of package $\mathrm{I} / \mathrm{O}$ 's is of equal importance when considering the use of alternative solder alloys. In those cases in which the lead or termination has a $\mathrm{Sn}-\mathrm{Pb}$ finish (and in some cases, so-called $\mathrm{Sn}$ finishes are actually high-Sn, $\mathrm{Sn}-\mathrm{Pb}$ compositions), that finish can be removed and replaced with an alternative composition in one of two approaches: (1) The $\mathrm{Sn}-\mathrm{Pb}$ is chemically stripped from the package and replaced with the preferred coating. (2) The $\mathrm{Sn}-\mathrm{Pb}$ finish is removed by immersing the lead or termination into a pot of molten solder or $\mathrm{Sn}$ as part of a hot-solder dipping procedure which literally washes the $\mathrm{Sn}-\mathrm{Pb}$ coating away. The latter process can be performed right in the plant following documented procedures with respect to pot contamination and change-out while the former approach typically requires that the work be done at an outside vendor. The choice of either procedure depends upon their compatibility with the particular package configuration, quantities, unit costs, etc. Presently, component vendors are becoming 
increasingly more flexible in terms of surface finishes that are available on their leaded products, particularly replacing the $\mathrm{Sn}-\mathrm{Pb}$ coatings with the Ni-Pd finish. Leadless chip carriers already have a $\mathrm{Ni} / \mathrm{Au}$ finish on the castellations; chip resistors and capacitors are readily available with $100 \mathrm{Sn}$ finishes over a $\mathrm{Ni}$ or $\mathrm{Cu}$ barrier layer that protects the underlying Ag thick-film contact.

In summary, the selection of a surface finish is an important function when considering the use of alternative solders for electronics assembly. Besides being compatible with the new solder composition so as to limit or prevent the formation of unwanted, low-melting temperature phases, the surface finish must also accommodate a wider range of process parameters and conditions, yet still provide adequate solderability protection. Of course, the alternative finish must not degrade the reliability of the solder joint later on when it is in service.

\section{Summary}

A overview has been presented on the topic of alternative surface finishes for package I/O's and circuit board features. A brief description of the function of the finish during the soldering operation was provided. Aspects of solderability protection, preferred coating thicknesses, wire bondability, and solder joint reliability were described for the following coatings: baseline hot-dipped, plated, and plated-and-fused 100Sn and $\mathrm{Sn}-\mathrm{Pb}$ coatings; $\mathrm{Ni} / \mathrm{Au} ; \mathrm{Pd}, \mathrm{Ni} / \mathrm{Pd}$, and $\mathrm{Ni} / \mathrm{Pd} / \mathrm{Au}$ finishes; and the recently marketed immersion Ag coatings. The Ni/Au coatings appear to be the best all-around option in terms of solderability protection and wire bondability. Nickel/Pd finishes offer a slightly reduced level of performance in these areas that is most likely due to variable Pd surface conditions. Irrespective of differences in processability, there is still a need to minimize dissolved $\mathrm{Au}$ or Pd contents in the solder material in order to maintain solder joint reliability. Ancillary aspects that included thickness measurement techniques; the importance of finish compatibility with conformal coatings and conductive adhesives; and the need for alternative finishes for the processing of non- $\mathrm{Pb}$ bearing solders were discussed.

\section{Acknowledgements}

The author wishes to thank Cynthia Hernandez for her thoughtful review of this manuscript.

\section{References:}


[1] P. Vianco, "An Overview of the Meniscometer/Wetting Balance Technique for Wettability [Solderability] Measurements," The Metal Science of Joining ed. by M. Cieslak, et al. (TMS, Warrendale, PA; 1991), p. 265.

[2] P. Vianco, F. Hosking, and J. Rejent, "Solderability Testing of Kovar with $60 \mathrm{Sn}-40 \mathrm{~Pb}$ Solder and Organic Fluxes," Welding J., Res. Suppl. 69 (1990), p. 230s.

[3] P. Vianco and A. Claghorn, "Effect of Substrate Preheating on Solderability

Performance as a Guideline for Assembly Development - Part 1: Baseline Analysis,"

Solder. and Surface Mount Tech. October (1996), p. 12.

[4] P. Vianco and A. Claghorn, "Effect of Substrate Preheating on Solderability

Performance as a Guideline for Assembly Development - Part 2: Baseline Analysis," Solder. and Surface Mount Tech. 9 (1997), p. 23.

[5] J. Bickerman, Surface Chemistry for Industrial Research (Academic Press, New York, NY; 1949), p. 124.

[6] P. Vianco "Embrittlement of Surface Mount Solder Joints by Hot-Dipped, Gold Plated Leads," Proc. Surface Mount Inter. August (1993), p. 337.

[7] D. Parquet and D. Boggs, "Alternatives to HASL: A User's Guide to Surface Finishes" Elect. Pack. And Prod. August (1995), p. 37.

[8] R. Prasad, "Key Attributes of Various Surface Finishes", Surface Mount Technology March (1997), p.32.

[9] K. Hoffer, "Solderability Testing of $\mathrm{Cu}_{6} \mathrm{Sn}_{5}$ Intermetallic," Proc. NEPCON West (1991), p.994.

[10] P. Vianco, P. Hlava, and A. Kilgo, "Intermetallic Compound Layer Formation Between Copper and Hot-Dipped 100In, 50In-50Sn, 100Sn, and 63Sn-37Pb Coatings," $J$. El.ect. Materials $\underline{23}$ (1994), p. 583.

[11] R. Fields, S. Low, and G. Lucey, "Physical and Mechanical Properties of Intermetallic Compounds Commonly Found in Solder Joints," The Metal Science of Joining, op. cit. p. 165.

[12] M. Ackroyd and C. MacKay, "Solders, Solderable Finishes and Reflowed Solder Coatings," Circuit World $\underline{3}$ January (1977) p. 2.

[13] R. Diehl and N. Cifaldi, "Elimination of Tin Whisker Growth on Interconnects," Proc 8th Annual Connector Symposium (1975), p. 328.

[14] R. Kuhl and S. Mills, "Assuring Whisker-Free Components," Surface Mount Tech. June (1995), p. 48.

[15] B. Dunn, "A Laboratory Study of Tin Whisker Growth," Report ESA STR-223, European Space Agency, Paris, France (1987). 
[16] K. Cunningham and M. Donahue, "Tin Whiskers: Mechanism of Growth and Prevention," Proc. 4th Inter. SAMPE Electronics Conf. June (1990), p. 569.

[17] V. Glaxunova and N. Nudryavstev, "An Investigation of Conditions of Spontaneous Growth of Crystals on Electrolytic Coatings," J. Applied Chem. USSR 36 (1963), p. 519. [18] T. Kakeshita, K. Shimizu, R. Kawanaka, and T. Hasegawa, "Grain Size Effect of Electro-plated Tin Coatings on Whisker Growth," J. Mater. Sci. 17 (1982), p. 2560. [19] U. Lindborg, "A Model for the Spontaneous Growth of Zinc, Cadmium, and Tin Whiskers," Acta Met. 24 (1976), p. 181.

[20] N. Sabbagh and H. McQueen, "Tin Whiskers: Causes and Remedies," Metal Finishing March (1975), p. 27.

[21] G. Stupian, "Tin Whiskers in Electronic Circuits," Report No. SMC-TR-93-18 (Space and Missile Systems Center, U.S. Air Force, Los Angeles Air Force Base, CA; 1992).

[22] L. Zakraysek, "Whisker Growth from A Bright Acid Tin Electrodeposit," Plating and Surface Finishing March (1977), p. 38.

[23] S. Arnold, "Repressing the Growth of Tin Whiskers," Plating 53 (1966), p. 95.

[24] K. Tu, "Irreversible Processes of Spontaneous Whisker Growth in Bimetallic Cu-Sn Thin Film Reactions," Phys. Rev. B 49 (1994) p. 2030.

[25] S. Britton, "Spontaneous Growth of Whiskers on Tin Coatings: 20 Years of Observations," Trans. Inst. of Metal Finish. $\underline{52}$ (1974), p;. 95.

[26] Y. Zhang, et al, "An alternative Surface Finish for Tin/Lead Solders: Pure Tin," Proc. Surface Mount Inter. Sept. (1996), p. 641.

[27] I. Artaki, U. Ray, A. Jackson, H. Gordon, and P. Vianco, "Solderability Preservative Coatings: Electroless Tin vs. Organic Azoles," Proc. Surface Mount Inter. August (1993) p. 414.

[28] R. Edgar, "Immersion White Tin: The Ideal Solderable Finish," Proc. Surface Mount Inter. August (1998), p. 632.

[29] D. Unsworth and C. Mackay, "A Preliminary Report on Growth of Compound Layers on Various Metal Bases Plated with Tin and it Alloys," Trans. Inst. Of Metal Finishing 51 (1973), p. 85.

[30] S. Crum, "Process Optimization with Organic Solderability Preservatives," Elect. Pack. and Prod. June (1996), p. 40.

[31] D. Verbockhaven, G. Conard, and K. McKean, "Using Nitrogen on OSP-Coated Printed Circuit Boards," Elect. Pack. and Prod., April (1997), p. 59.

[32] H. Hsiao, J. Lin, E. Chang, and S. Adams, "Reduction of Solder Defects Under Nitrogen," Surface Mount Technology January (1998), p. 56. 
[33] I. Artaki, U. Ray, H. Gordon, and R. Opila, "Corrosion Protection of Copper Using Organic Solderability Preservatives," Proc. Surface Mount Inter., (1992), p. 503.

[34] P. Vianco, I. Artaki, and A. Jackson, "Reliability Studies of Surface Mount Boards Manufactured with Lead-Free Solders," Proc. Surface Mount Inter., (1994), p. 437. [35] I. Artaki, A. Jackson, and P. Vianco, "Fine-Pitch Surface Mount Assembly with Lead-Free, Low Residue Solder Paste," ibid., p. 449.

[36] I. Artaki, D. Finley, A. Jackson, U. Ray, and P. Vianco, "Wave Soldering with Lead-Free Solders," Proc. Surface Mount Inter. (1995), p. 495.

[37] P. Vianco and C. May, "An Evaluation of Prototype Surface Mount Circuit Boards Assembled with Three Non-Lead Bearing Solders," ibid., p. 481.

[38] Kovar ${ }^{\mathrm{TM}}$ and Alloy $42^{\mathrm{TM}}$ are registered trademarks of Carpenter Technologies.

[39] J. Poate, "Diffusion and Reactions in Gold Films," Gold Bull. 14 (1981), p. 2.

[40] J. Abbott, "Autocatalytic Nickel Process," Advanced Mater. And Process, " December (1996), p. 21.

[41] B. Bingle, C. Rice, and T. Vogel, "Electroless Nickel/Gold Plating for Chip-on Board," Elect. Pack. And Prod. October (1992), p. 60.

[42] J. Coderre, L. Guerin, and R. Langlois, "Selective Electroless Gold Plating for Mixed Interconnections," Proc. of the Technical Conference - IPC Expo. March (1997), p. S166-1.

[43] M. Bester, "Metallurgical Aspects of Soldering Gold and Gold Plating, "Proc. InterNECON (1969), p. 211.

[44] R. Duckett and M. Ackroyd, "The Influence of Solder Compositions on the Embrittlement of Soft-Soldered Joints on Gold Coating," Electroplating and Metal Finishing, May (1976), p. 13.

[45] Z. Mei, M. Kaufmann, A. Eslambolchi, and P. Johnson, "Brittle Interfacial Fracture of PBGA Packages Soldered on Electroless Nickel/Immersion Gold," Proc. 48 ECTC May (1998), p. 952.

[46] F. Houghton, "Alternative Metallic Finishes for PWB - An ITIR/October Project," Proc. of the Technical Conference - IPC Expo March (1997), p. S16-4-1.

[47] P. Kay and C. Mackay, "Barrier Layers Against Diffusion," Trans. Inst. of Metal Finishing $\underline{57}$ (1979), p. 169.

[48] R. Pratt, Eric Stromweld, and D. Quesnel, "The Effect of Gold, Silver, and Palladium Contamination on the Mechanical Properties of Cu/63Sn-37Pb Solder Joints," Sandia Report SAND93-7104, Sandia National Laboratories, Albuquerque, NM, Sept. 1993. 
[49] D. Abbott, R. Brook, N. McLelland, and J. Wiley, "Palladium as a Lead Finish for Surface Mount Integrated Circuit Packages," IEEE Trans. On Comp., Hybrids, and Manuf. Tech., 14 (1991), p. 568.

[50] D. Finley, U. Ray, I. Artaki, P. Vianco, S. Shah, A. Reyes, and M. Haq, "Assessment of Nickel-Palladium Finished Components for Surface Mount Assembly Application," Proc. Surface Mount Inter. (1995), p. 941.

[51] D. Cullen, "Wirebonding to Electrolessly Deposited Metallic Circuit Board Finishes," Proceeding of the Technical Conference - IPC Expo. March (1997), p. S16-2-1.

[52] R. Johnson, V. Wang, and M. Palmer, "Thermal Cycle Reliability of Solder Joints to Alternate Plating Finishes," Proc. Surface Mount Inter. (1998), p. 681.

[53] G. Milad, "Surface Finishes: Metallic Coatings over Nickel over Copper," Proc. Surface Mount Inter. (1996), P. 794.

[54] D. Hillman, P. Bratin, and M. Pavlov, "Wirebondability and Solderability of Various Metallic Finishes for Use in Printed Circuit Assembly," Proc. Surface Mount Inter. (1996), p. 687.

[55] Z. Mei and A. Eslambolchi, "Evaluation of Ni/Pd/Au As an Alternative Metal Finish on PCB," Proc. Surface Mount Inter., August (1998), p. 669.

[56] E. Bernedetto, "Solderability and Board Level Reliability of Palladium Plated, Fine Pitch Components, " Proc. Surface Mount Inter. Aug. (1998), p. 624.

[57] W. Bader, "Dissolution of Au, Ag, Pd, Pt, Cu and Ni in a Molten Tin-Lead Solder," Welding J. 48 (1969), p. 80s.

[58] R. Klein-Wassink, Soldering in Electronics (Electrochem. Pub., Ltd., Ayr, Scotland, UK; 1989), p. 179.

[59] D. Frear, F. Hosking, and P. Vianco, "Mechanical Behavior of Solder Joint Interfacial Intermetallics," Materials Developments in Microelectronic Packaging:

Performance and Reliability, ed. by P. Singh (ASM, Materials Park, 1991), p. 229.

[60] G. Humpston and D. Jacobson, "Principles of Soldering and Brazing," (ASM Inter., Materials Park, OH; 1993), p. 150.

[61] P. Kay and C. Mackay, " The Growth of Intermetallic Compounds on common Basis Materials Coated with Tin and Tin-Lead Alloys," Trans. Inst. of Metal Finishing $\underline{54}$ (1976), p. 68.

[62] S. Biegle, "Non-Precious Metal Coatings for Fine Pitch Assembly and Direct Chip Attachment," Proc. Surface Mount Inter. Sept. (1996), p. 780.

[63] S. Biegle; D. Hillman, P. Bratin, and M. Pavlov, "Wirebondability and Solderability of Various Metallic Finishes for Use in Printed Circuit Assembly," Proc. Surface Mount Inter. Sept. (1996), p. 687. 
[64] R. Iman and J. Koon, "A Multi-Organizational Evaluation of Conformal-Coating Applications and Alternative Surface Finishes for Circuit-Card Assemblies," Proc. of the Technical Conf.-IPC Expo March (1997), p. S16-7-1.

[65] P. Vianco, D. Frear, F. Yost, and J. Roberts, "Development of Alternatives to Pbbased Solders," Sandia Report SAND97-0315, Sandia National Laboratories, Albuquerque, NM 1997.

[66] W. Silverman, "XRF Measurements of the Composition and Thickness of Electrodeposited Pd-Ni Alloy," Metal Finishing January (1989), p. 57.; R. Christensen, "Coating Thickness," Quality February (1989), p. 38.

[67] R. Christensen, "Coating Thickness," Quality February (1989), p. 38.

[68] J. London and D. Ashall, "Compound Growth and Fracture at Copper/Tin-Silver Solder Interfaces," Brazing and Soldering (Autumn (1986), p. 49.

[69] D. Frear and P. Vianco, "Intermetallic Growth and Mechanical Behavior of Low and High Melting Temperature Solder Alloys," Metall. Trans. A 25A (1994), p. 1509. [70] J. Jellison, "Kinetics of Thermocompression Bonding to Organic Contaminated Gold Surfaces," IEEE Trans. On Parts, Hybrids, and Packaging PHP-13 (1977), p. 132. [71] J. Jellison, "Effect of Surface Contamination on the Thermocompression Bondability of Gold," IEEE Trans. on Parts, Hybrids, and Packaging PHP-11 (1975), p. 206. [72] B. Bingle, C. Rice, and T. Vogel, "Electroless Nickel/Gold Plating for Chip-onBoard," Elect. Pack. And Prod. October (1992), p. 60.

[73] J. Reed, "NCMS Surface Finish Testing," Proc. Surface Mount Inter. Sept. (1996), p. 797.

[74] P. Vianco, J. Rejent, I. Artaki, U. Ray, D. Finley, and A. Jackson, "Compatibility of Lead-Free Solders with Lead-Containing Surface Finishes as a Reliability Issue in Electronic Assemblies," Proc. 46 ${ }^{\text {th }}$ ECTC May (1996), p. 1172.

[75] J. Glazer, "Metallurgy of Low Temperature Pb-free Solders for Electronic Assembly," Intern. Mater. Revs. $\underline{40}$ (1995), p. 65.

[76] A. Jackson, I. Artaki, and P. Vianco, "Manufacturing Feasibility of Several Lead-Free Solders for Electronics Assembly, " Proc. $7^{\text {th }}$ Inter. SAMPE Conference June (1994), p. 381.

[77] P. Vianco and P. Mizik, "Prototyping Lead-Free Solders on Hand-Soldered, Through-Hole Circuit Boards," Proc. $7^{\text {th }}$ Inter. SAMPE Conference June (1994), p. 366. [78] D. Jacobson and G. Humpston, "Gold Coatings for Fluxless Soldering," Gold Bull. $\underline{22}$ (1989), p. 9. 
[79] P. Vianco and J. Rejent, "Prototype Circuit Boards Assembled with Non-Lead Bearing Solders," Proc. Third Pacific Rim Inter. Conf. On Adv. Mater. And Proc. July (1998), p. 2571.

[80] U. Ray, et al., "Assessment of Circuit Board Surface Finishes for Electronic Assembly with Lead-Free Solders," Proc. Surface Mount Inter. September (1996), p. 656.

\section{Figure Captions}

Fig. 1 Flow of molten solder on: (a) horizontal surface, (b) vertical surface, (c) horizontal gap (hole), and (d) vertical gap (hole).

Fig. 2 Sessile drop of molten solder on a (a) horizontal surface and (b) vertical surface, showing the physical relationships between the interfacial tension terms and contact angle $\left(\theta_{\mathrm{c}}\right)$.

Fig. 3 Schematic diagram of the phenomena that occur to the solderable and protective finishes during the wetting and spreading of molten solder.

Fig. 4 Interface structure that develops when a portion of the protective finish is retained after soldering, and is subsequently converted to an intermetallic compound layer under solid-state diffusion processes with the overlaying solder coating. Although illustrated with a solderable coating, this scenario would also occur for protective layers applied directly over the base material.

Fig. 5 Schematic diagram of the hot-air solder leveling (HASL) technique used to apply hot-solder coatings to printed circuit board features.

Fig. 6 Accumulation of the $\mathrm{Pb}$ rich layer at the interface between the intermetallic compound layer and $63 \mathrm{Sn}-37 \mathrm{~Pb}$ solder after aging at $135^{\circ} \mathrm{C}$ for 400 days.

Fig. 7 SEM micrograph of cracks that developed in the Ni/Pd finish on a TSOP, $\mathrm{Cu}$ lead as a result of the lead forming process.

Fig. 8 SEM micrograph of the solder joint of a $0.5 \mathrm{~mm}$ pitch TSOP lead showing the gap region (B) and fillet region (A). 
Fig. 9 Schematic diagram of the solder joint structure having the base material, solderable coating, and the solder. 
$\overline{\dot{s}}$
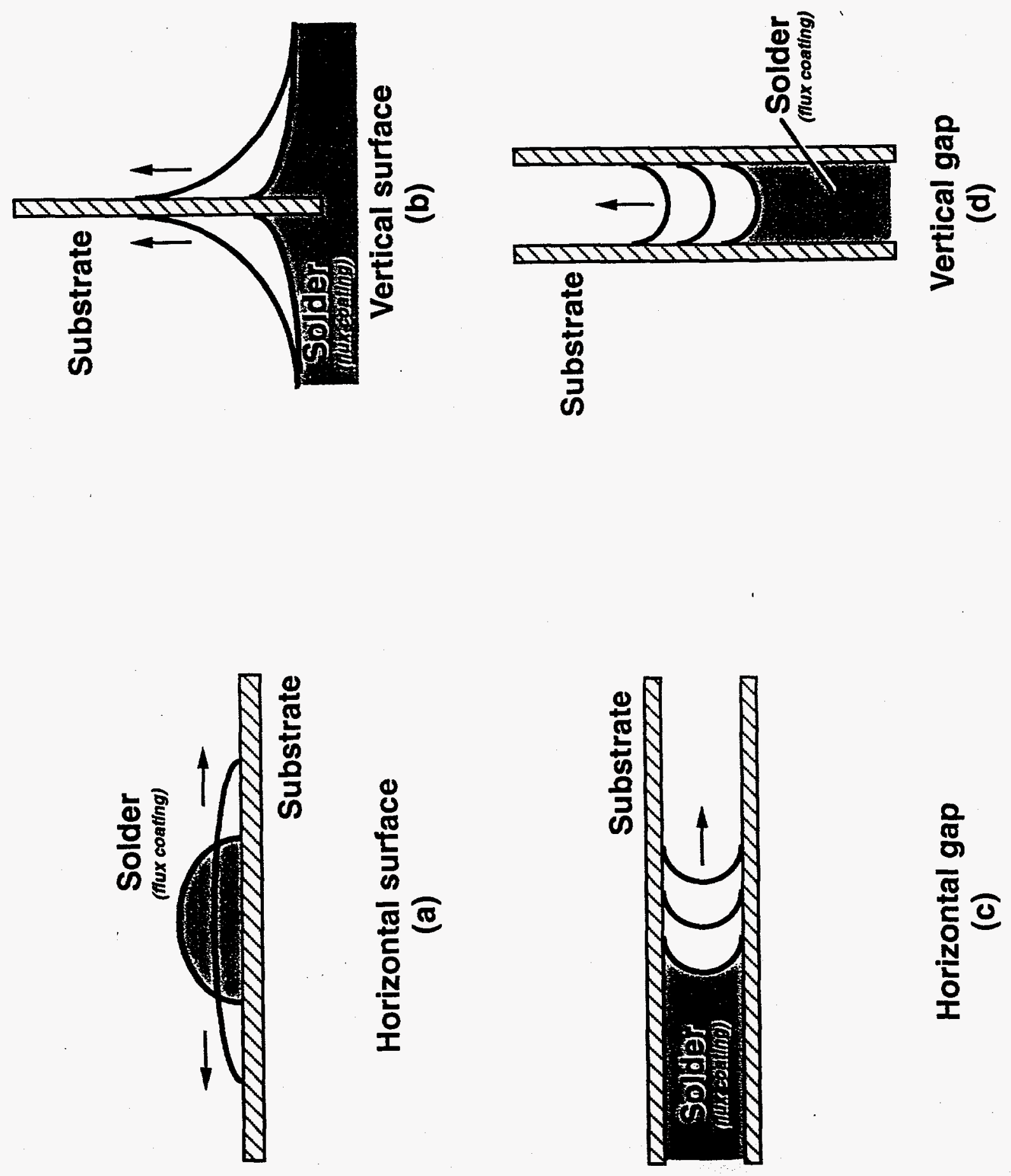


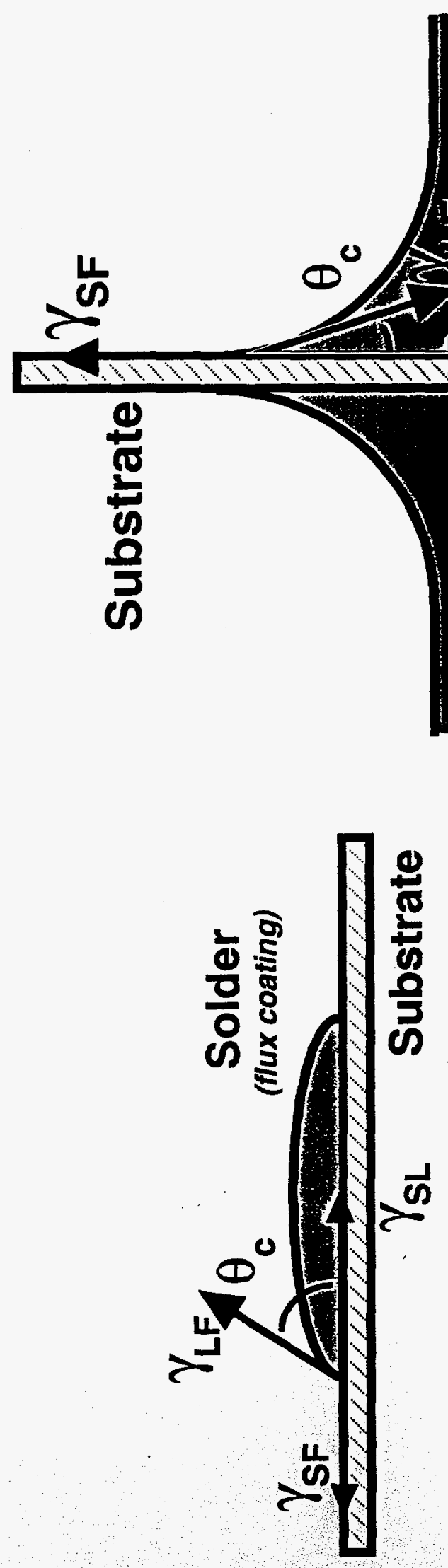

竎
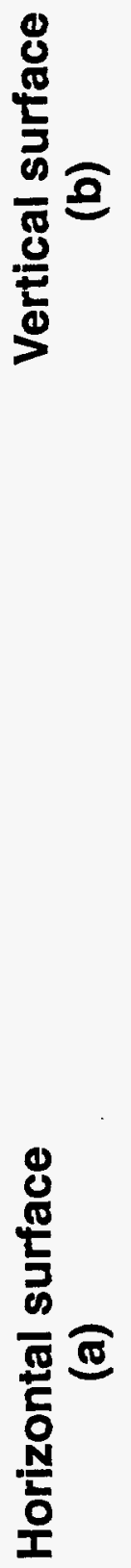


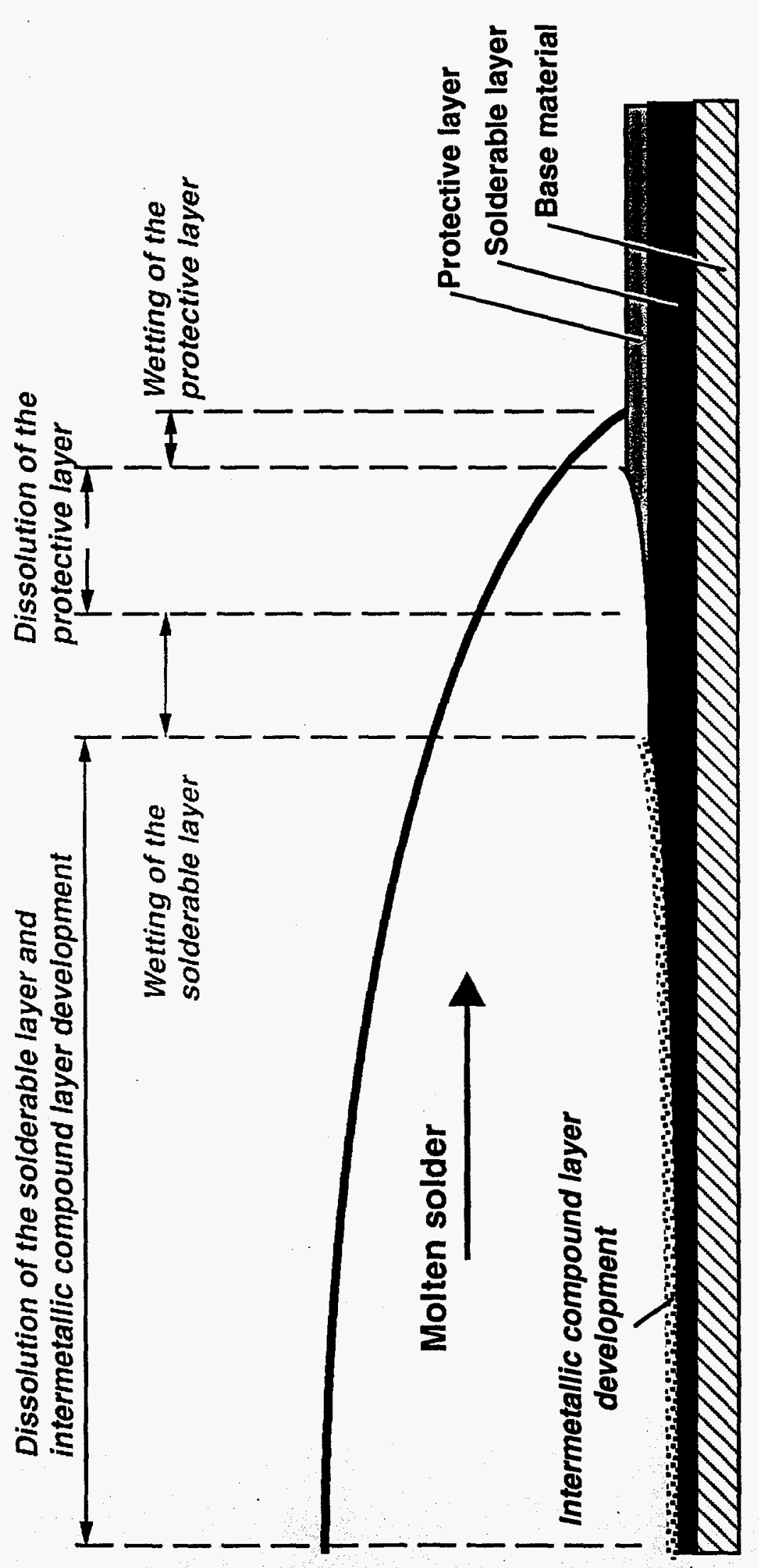

它 


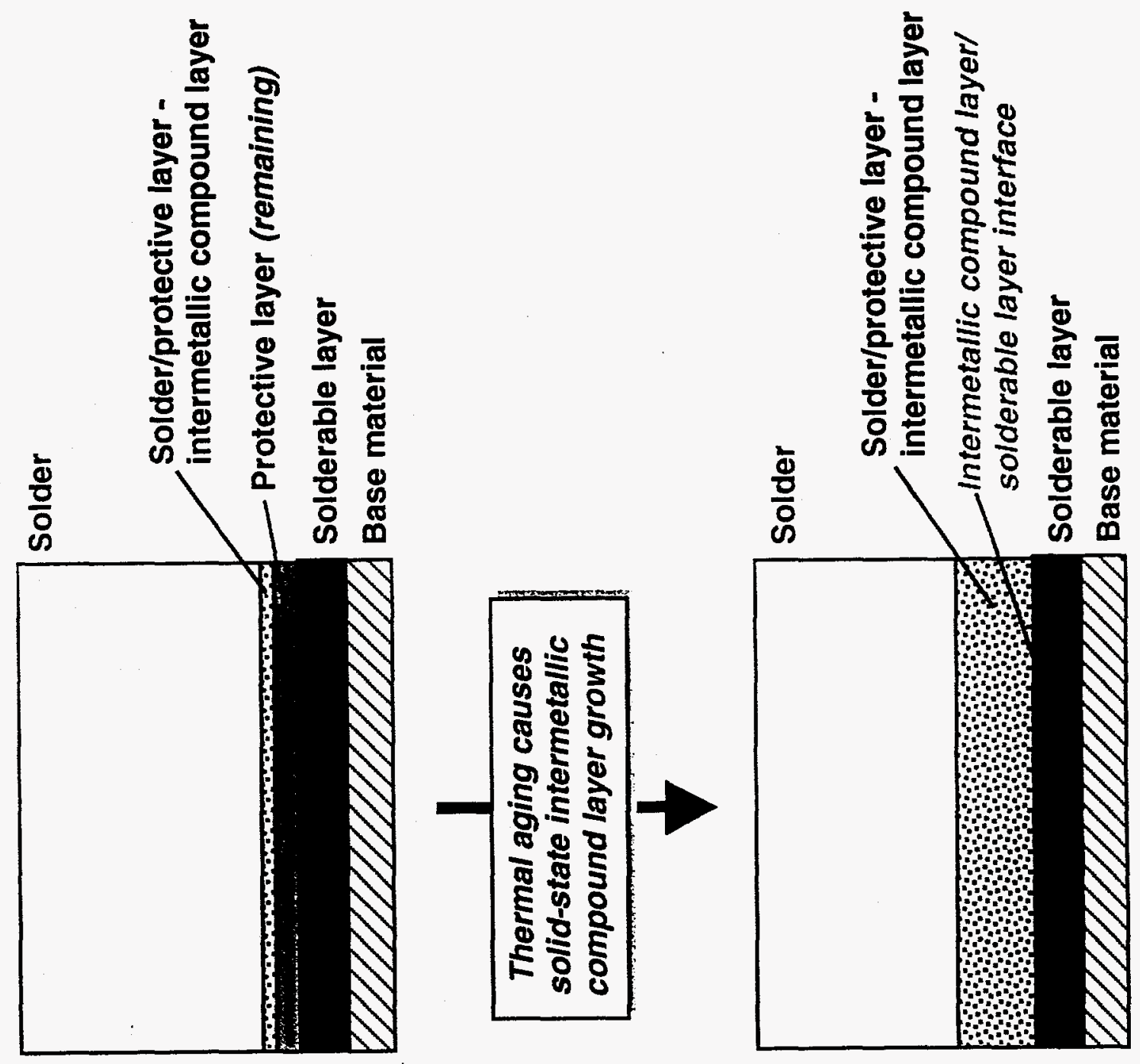



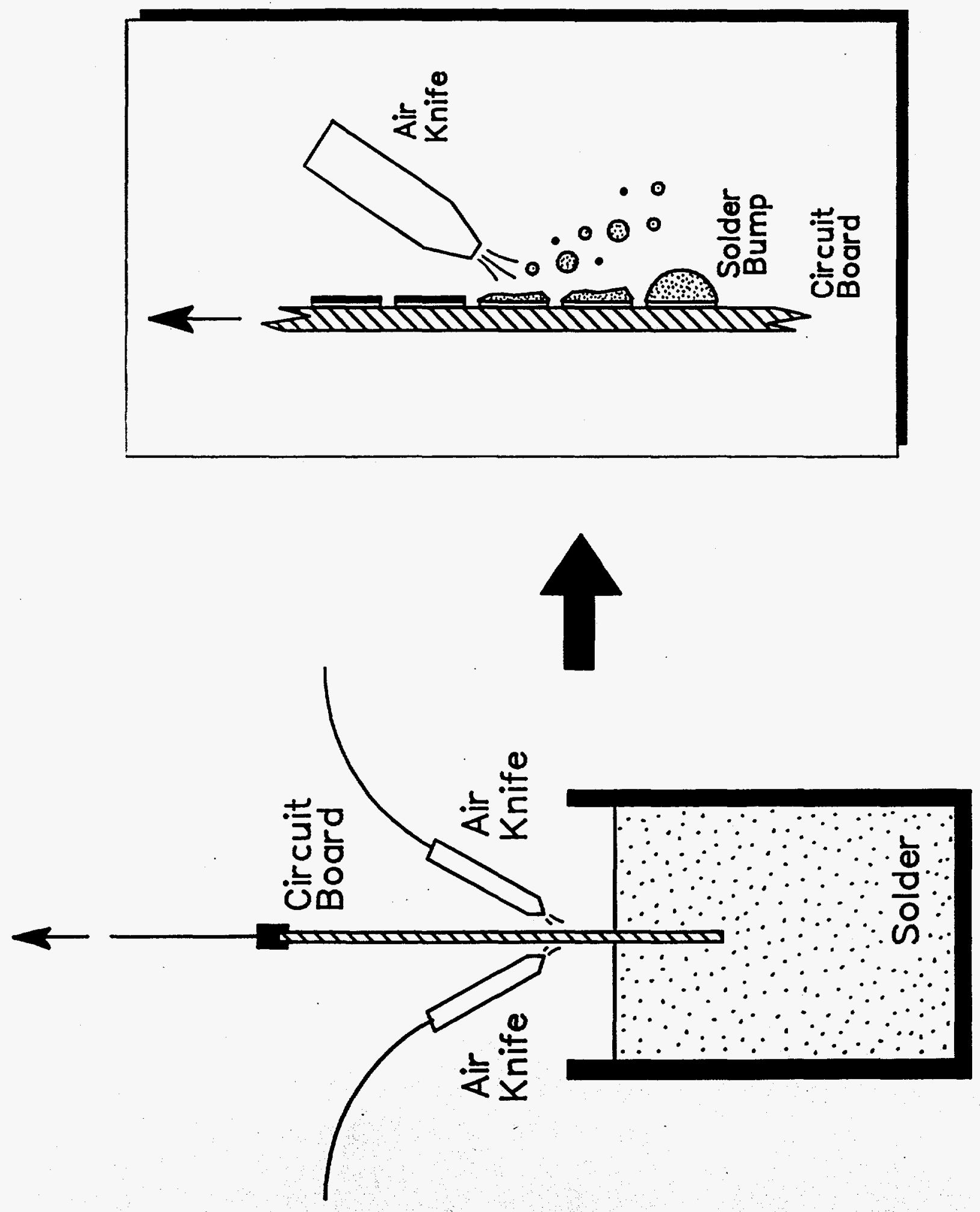


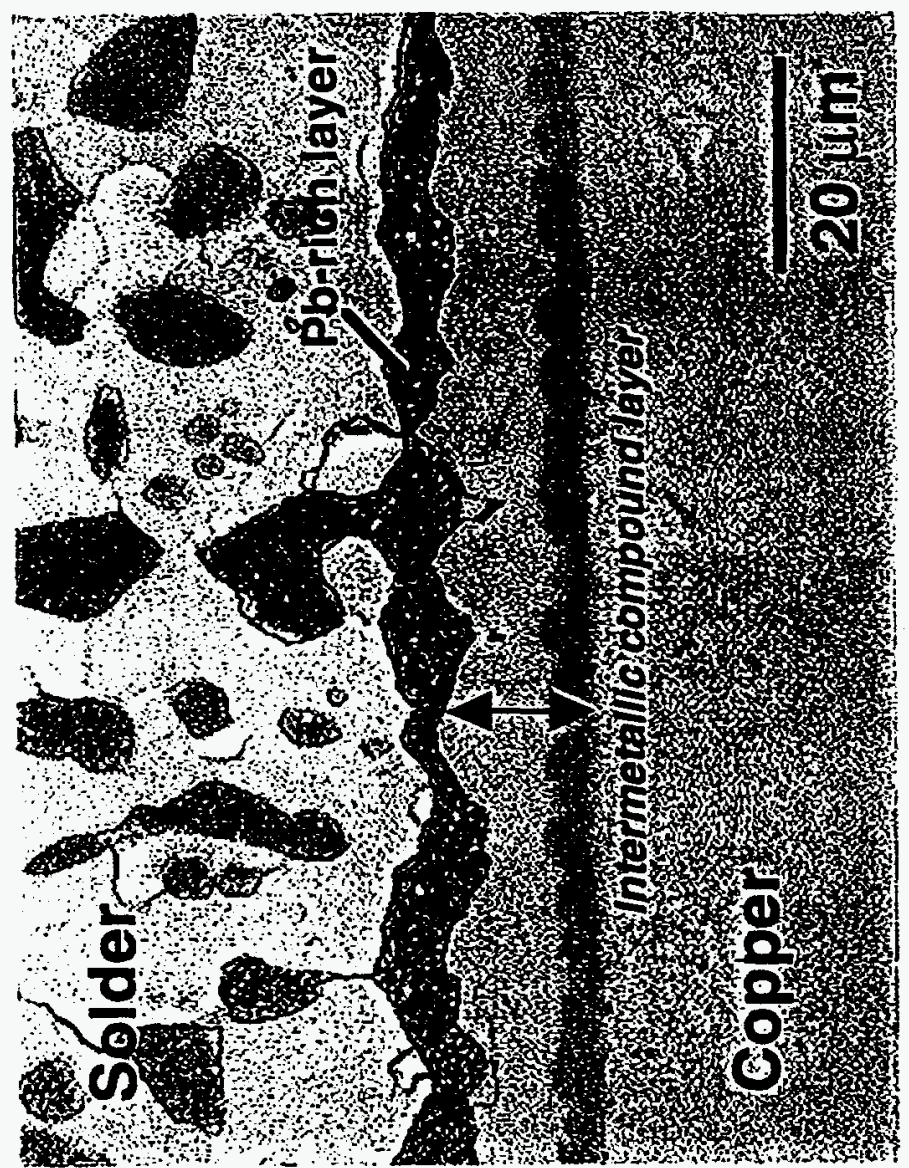


호

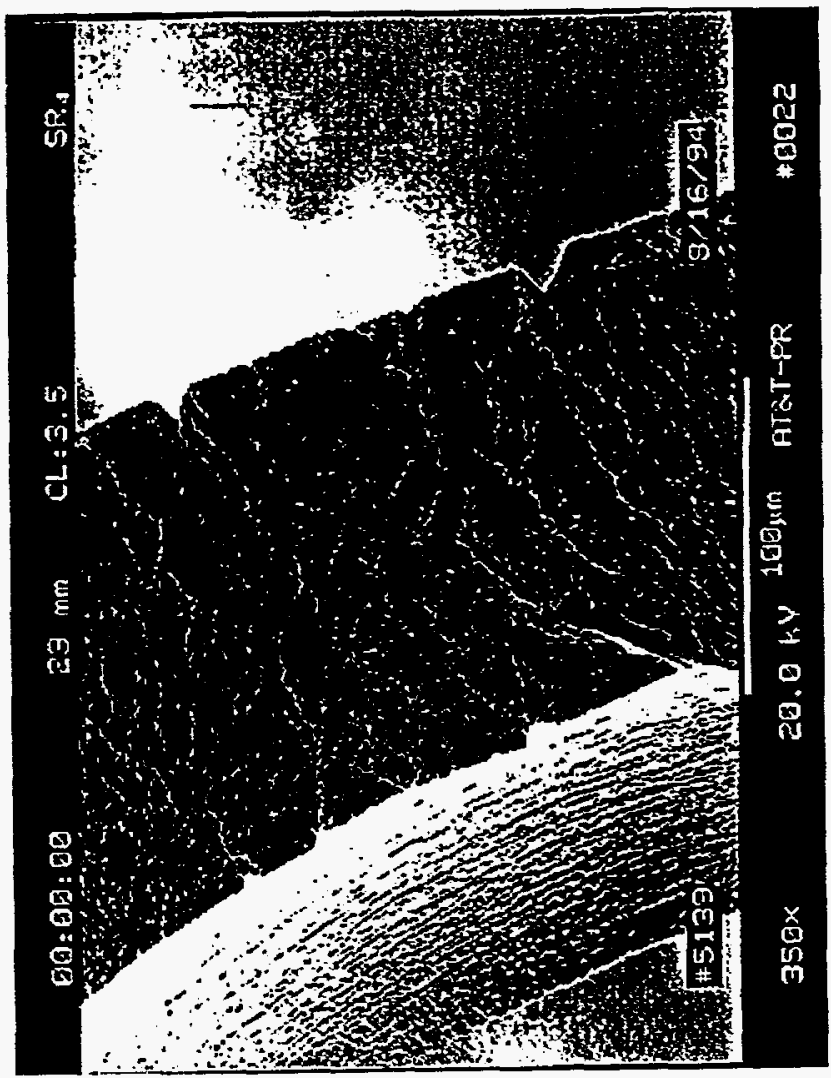




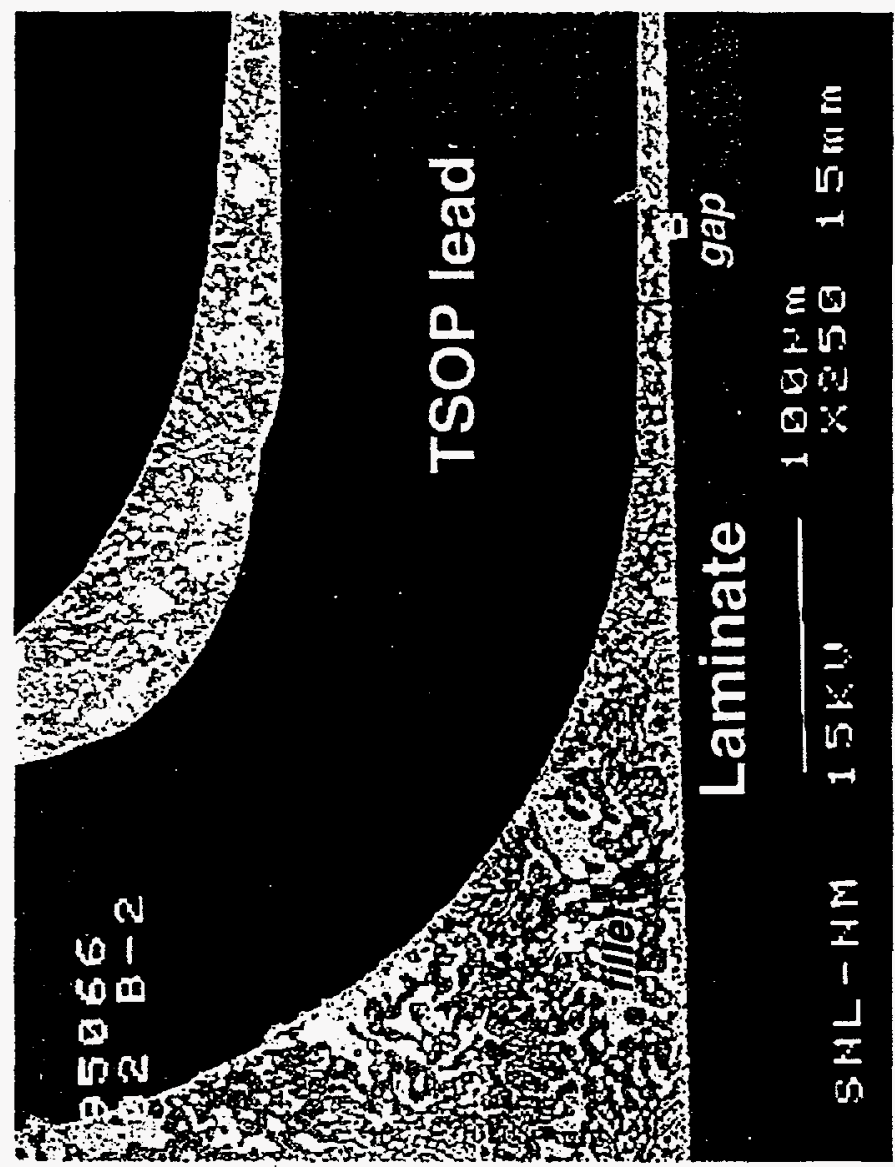




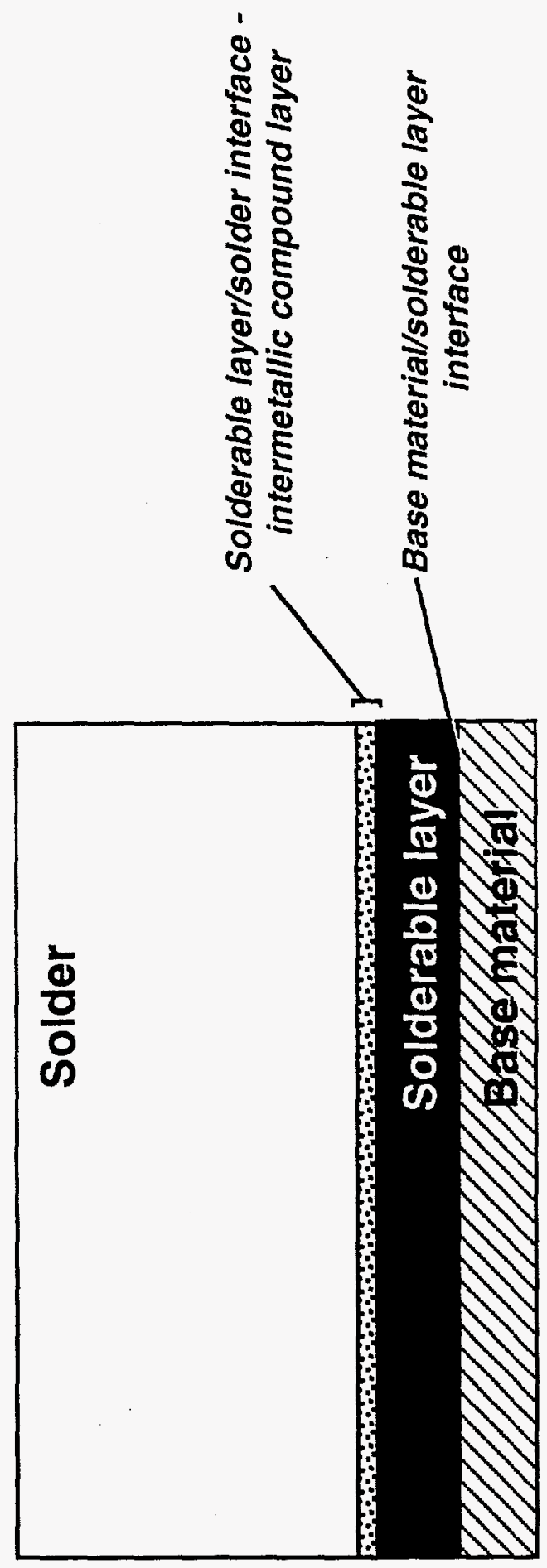

